\title{
ARTICLE
}

\section{Gas diffusion electrode design for electrochemical carbon dioxide reduction}

Received 00th January 20xx, Accepted 00th January 20xx DOI: $10.1039 / x 0 \times x 00000 x$

\begin{abstract}
Tu N. Nguyen ${ }^{a, b, *}$, Cao-Thang Dinh ${ }^{a, *}$
Anthropogenic carbon dioxide $\left(\mathrm{CO}_{2}\right)$ emissions contribute to the greenhouse effect and global warming, which can lead to undesirable climate change and extinction of species. Besides the ongoing efforts to develop environmentally benign sources of energy and to advance technologies for the capture and sequestration of $\mathrm{CO}_{2}$, the transformation of emitted $\mathrm{CO}_{2}$ into valuable products is a pragmatic solution to curb its accumulation in the atmosphere. In this regard, electrochemical $\mathrm{CO}_{2}$ reduction (ECR) powered by renewable electricity provides an attractive approach because it not only converts $\mathrm{CO}_{2}$ to valuable fuels and chemicals but also offers a solution for the long-term storage of intermittent renewable energies. In ECR, the gas diffusion electrode (GDE) is the most critical component and has been the subject of intensive research in the last few years. This tutorial review provides an insightful guide to develop GDE with high activity, selectivity, and stability, the three important performance metrics in ECR. First, we introduce critical fundamentals of ECR, including the chemical and physical phenomena at the electrodes as well as the electrochemical cell configurations. Next, we discuss recent advances in GDE design, focusing on their structure-performance correlation and fabrication techniques for each component of GDEs. Finally, we discuss the remaining challenges and propose promising research directions for the design of efficient GDEs. This review aims at promoting the development of industrially relevant ECR systems to bring this technology to practical applications.
\end{abstract}
Key learning points:
(1) Fundamental design and working principles of electrochemical $\mathrm{CO}_{2}$ reduction system.
(2) Structure and principle design of the gas diffusion electrode.
(3) Fabrication methods for the gas diffusion layer and the catalyst.
(4) Recent significant advances in the development of the gas diffusion electrode.
(5) Current challenges and promising research directions for electrochemical $\mathrm{CO}_{2}$ reduction.

\section{Introduction}

The greenhouse effect is one of the most daunting challenges facing humanity because it induces the gradual increase of the atmospheric temperature, known as global warming, and can lead to undesirable climate change and the extinction of species. Carbon dioxide $\left(\mathrm{CO}_{2}\right)$ is the main greenhouse gas, accumulating in the air due to human activities such as the burning of fossil fuels and clearcutting of forests. Reducing $\mathrm{CO}_{2}$ emissions is widely acknowledged as a major international research priority to avoid the greenhouse effect. Achieving this target will require efforts in shifting traditional fossil fuels to low-carbon renewable energy sources, developing technologies for the capture and sequestration of $\mathrm{CO}_{2}$, and converting emitted $\mathrm{CO}_{2}$ into valuable products. ${ }^{1}$

\footnotetext{
a. Department of Chemical Engineering, Queen's University, Kingston, ON, Canada, KTL $3 N 6$.

b. Helen Scientific Research and Technological Development Co., Ltd, Ho Chi Minh City, Vietnam

Electronic Supplementary Information (ESI) available: See DOI: 10.1039/x0xx00000x
}

Renewable energies such as wind and solar are widely distributed and, taken together, could exceed today's global electricity demand by 10,000 -fold. However, the intrinsic intermittency of solar and wind resources limits their further deployment as replacements of fossil fuels. Electrochemical $\mathrm{CO}_{2}$ reduction (ECR), which employs renewable electricity as an energy source to convert $\mathrm{CO}_{2}$ to fuels and chemicals, simultaneously addresses the $\mathrm{CO}_{2}$ emission and the intermittency issue of renewable energy sources. The recycling $\mathrm{CO}_{2}$ will result in a low- or zero-carbon fuel, which can be readily integrated into current infrastructures. Converting $\mathrm{CO}_{2}$ into chemical feedstocks can also enable the sequestration of $\mathrm{CO}_{2}$ into long-lifetime products such as polymers, suggesting the high potential of ECR as a pragmatic solution to curb the $\mathrm{CO}_{2}$ emission and to tackle the greenhouse effect. ${ }^{2}$

The main challenge for ECR is that many products produced via this reaction are also industrially produced from fossil feedstocks at a low cost. This prompts the need for the design of systems capable of driving the $\mathrm{CO}_{2}$ reduction with high performance to make them economically competitive. ${ }^{3}$ For the last decades, ECR research has mainly focused on developing 
active and selectivity catalysts. Significant advances in the reduction of $\mathrm{CO}_{2}$ to many products, including carbon monoxide (CO), formic acid $(\mathrm{HCOOH})$, methane $\left(\mathrm{CH}_{4}\right)$, ethylene $\left(\mathrm{C}_{2} \mathrm{H}_{4}\right)$, and ethanol $\left(\mathrm{C}_{2} \mathrm{H}_{5} \mathrm{OH}\right)$ with relatively high selectivity have been achieved. However, these improvements are often limited to low current densities. ${ }^{4}$ This is because ECRs are performed in an aqueous system, in which the catalysts are immersed in a liquid electrolyte, and $\mathrm{CO}_{2}$ is provided from the bulk solution. In that system, the low solubility of $\mathrm{CO}_{2}$ in the aqueous electrolyte (34 $\mathrm{mM}$ ) and the long diffusion distance of the gas molecules from the bulk solution to the electrode limit the amount of $\mathrm{CO}_{2}$ availability on the surface of the catalysts. Thus, the limiting current densities are often below a few tens of $\mathrm{mA} / \mathrm{cm}^{2}$, which are far from the $>300 \mathrm{~mA} / \mathrm{cm}^{2}$ regime needed to make ECR economically viable. ${ }^{1,5}$

The gas-phase ECR overcomes the diffusion limitation of the aqueous system, enabling orders of magnitude higher current densities; therefore, attracting great attention in recent years. ${ }^{6-}$ 8 The critical component in the gas-phase ECR that helps overcome the diffusion limitation is the gas diffusion electrode (GDE), where $\mathrm{CO}_{2}$ is converted into desired chemicals and fuels. The GDE comprises a catalyst layer deposited onto a porous hydrophobic substrate, i.e., the gas diffusion layer (GDL). Using $\mathrm{GDE}$, the $\mathrm{CO}_{2}$ gas reactant reaches the catalyst surface through the GDL, significantly shortens the diffusion path of $\mathrm{CO}_{2}$ in the electrolyte, and enables GDE to operate at very high current densities. The GDE also provides opportunities to tune the reaction environment (i.e., using alkaline electrolyte) to improve both activity and selectivity, which could not be achieved otherwise. ${ }^{7,} 9$ Because the transport of the reactant and the reaction environment play vital roles, the efficiency of the ECR depends not only on the active catalyst but also on the overall structure and composition of the GDE.

In this review, we discuss the development of GDE for gasphase ECR, focusing on principles underlying recent GDE designs that show high performance. First, we provide a brief overview of the fundamentals of the reactions at the electrodes as well as different electrochemical cell configurations. Next, we discuss the structure, fabrication, and functions of each component in the GDEs, particularly focusing on the structureperformance correlation. Finally, we conclude by highlighting the remaining challenges facing GDE design and proposing promising research directions to move this field forward.

\section{Gas-phase electrochemical $\mathrm{CO}_{2}$ reduction}

ECR systems are based on the established configurations of water electrolyzers and fuel cells, which consist of three main components: a cathode, an anode, and a membrane (Fig. 1a). $\mathrm{CO}_{2}$ gas is reduced to desired products at the cathode, while water is usually oxidized at the anode side to generate oxygen and protons. The cathode and anode are often separated by an ion-exchange membrane to help balance the ionic charge while preventing the migration of products to the opposite electrode. The efficiency of an ECR system depends on the kinetics of the reactions occurring at the two electrodes, the ions transport through the electrolyte the membrane, and the diffusion of
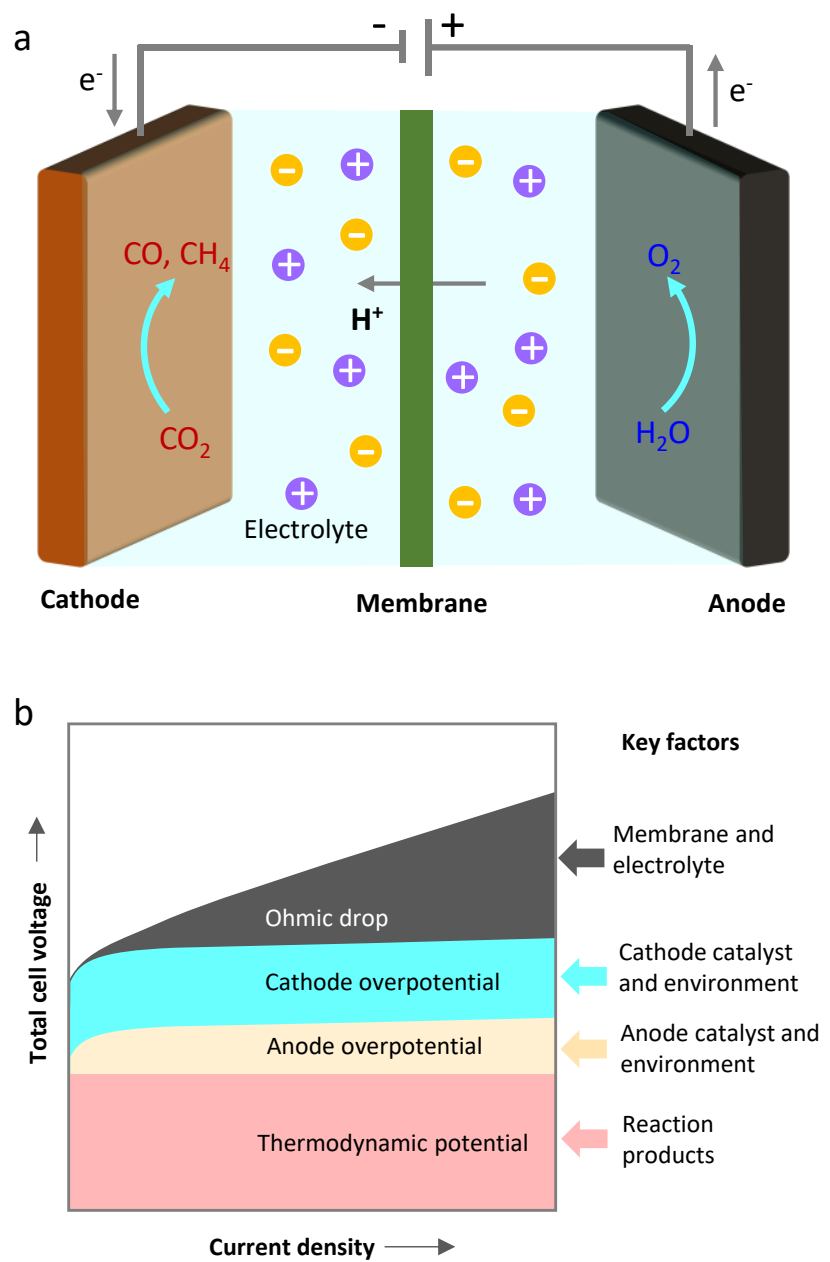

Fig. 1. a) A typical ECR system which involves a cathode, an anode, and a membrane separating these two electrodes. The ions in the electrolyte facilitate the charge transport. b) Breakdown of overall cell voltage as a function of current density showing the effect of key components.

reactants and products in the system. The sections below aim to give some fundamentals about some key performance metrics, the chemistry at cathode, anode, and membrane, as well as the design of the electrochemical cell for gas-phase ECR.

\subsection{Electrochemical $\mathrm{CO}_{2}$ reduction fundamentals}

\subsubsection{Key performance metrics}

The efficiency of an ECR system is characterized by several performance metrics that govern the capital and operational costs of the whole process. The main performance metrics include Faradaic efficiency, current density, energy efficiency, and stability. The Faradaic efficiency, defined as the percentage of the charge consumed to produce a given product over the total charge consumed, reflects the selectivity toward a specific ECR product. A high Faradaic efficiency minimizes downstream product separation requirements and reduces the total current required for a target production rate. The current density reflects the reaction rate of ECR. Usually, geometric current density, which is defined as the electrical current flow per geometric area, is used to evaluate the efficiency of the ECR system. High current density is desirable for reducing capital 
costs but often reduces the stability of the ECR system. In addition, operating at high current densities lowers the energy efficiency of the system because of a large Ohmic drop.

The energy efficiency is the percentage of the energy stored in the desired products compared to the total input energy which is proportional to the total cell voltage. High energy efficiency is important to reduce the cost of electricity required. Increasing energy efficiency means decreasing total cell voltage, which involves thermodynamic cell voltage, cathode and anode overpotentials, and ohmic potential drop (Fig. 1b). The thermodynamic cell voltage, defined as the difference between the thermodynamic potentials of the cathodic and anodic reactions, is a constant and is dependent on the products generated at the two electrodes. The overpotential is the difference between the thermodynamic potential and the actual potential at which a given reaction (both cathode and anode) occurs at a specific current density. It is a sum of overpotentials associated with different reaction steps at the electrodes, including both mass-transfer and charge-transfer overpotentials. The ohmic potential drop, caused by current flow in electrolyte and membrane, is governed by the ionic conductivity of these media and increases with increasing current density. Finally, the stability is also a critical aspect of evaluating the efficiency of ECR because it governs the maintenance and replacement costs, as well as associated electrolyzer downtime. In ECR, the anode has been welldeveloped thanks to the water electrolyzer technology Currently, cathode and membrane are the two key components limiting the stability of the ECR system.

\subsubsection{Cathodic reactions}

The cathode is the negative terminal in the $\mathrm{CO}_{2}$ electrolyzer, where $\mathrm{CO}_{2}$ molecules are reduced on the surface of an electrocatalyst by reacting with electrons $\left(\mathrm{e}^{-}\right)$and protons $\left(\mathrm{H}^{+}\right)$. Depending on the number of electrons and protons transferred different products, including carbon monoxide and formic $\left(2 \mathrm{H}^{+}\right.$ $\left.+2 \mathrm{e}^{-}\right)$, formaldehyde $\left(4 \mathrm{H}^{+}+4 \mathrm{e}^{-}\right)$, methanol $\left(6 \mathrm{H}^{+}+6 \mathrm{e}^{-}\right)$, methane $\left(8 \mathrm{H}^{+}+8 \mathrm{e}^{-}\right)$, ethylene and ethanol $\left(12 \mathrm{H}^{+}+12 \mathrm{e}\right)$ can be obtained (equations 1-7, E ${ }^{\circ}$ is thermodynamic potential vs. reversible hydrogen electrode (RHE)).

$$
\begin{array}{ll}
\mathrm{CO}_{2}+2 \mathrm{H}^{+}+2 \mathrm{e}^{-} \rightarrow \mathrm{CO}+\mathrm{H}_{2} \mathrm{O} & \mathrm{E}^{\circ}=-0.11 \mathrm{~V} \\
\mathrm{CO}_{2}+2 \mathrm{H}^{+}+2 \mathrm{e}^{-} \rightarrow \mathrm{HCOOH} & \mathrm{E}^{\circ}=-0.21 \mathrm{~V} \\
\mathrm{CO}_{2}+4 \mathrm{H}^{+}+4 \mathrm{e}^{-} \rightarrow \mathrm{HCHO}+\mathrm{H}_{2} \mathrm{O} & \mathrm{E}^{\circ}=-0.10 \mathrm{~V} \\
\mathrm{CO}_{2}+6 \mathrm{H}^{+}+6 \mathrm{e}^{-} \rightarrow \mathrm{CH}_{3} \mathrm{OH}+\mathrm{H}_{2} \mathrm{O} & \mathrm{E}^{\circ}=0.03 \mathrm{~V} \\
\mathrm{CO}_{2}+8 \mathrm{H}^{+}+8 \mathrm{e}^{-} \rightarrow \mathrm{CH}_{4}+2 \mathrm{H}_{2} \mathrm{O} & \mathrm{E}^{\circ}=0.17 \mathrm{~V} \\
2 \mathrm{CO}_{2}+12 \mathrm{H}^{+}+12 \mathrm{e}^{-} \rightarrow \mathrm{C}_{2} \mathrm{H}_{4}+4 \mathrm{H}_{2} \mathrm{O} & \mathrm{E}^{\circ}=0.07 \mathrm{~V} \\
2 \mathrm{CO}_{2}+12 \mathrm{H}^{+}+12 \mathrm{e}^{-} \rightarrow \mathrm{C}_{2} \mathrm{H}_{5} \mathrm{OH}+3 \mathrm{H}_{2} \mathrm{O} & \mathrm{E}^{\circ}=0.09 \mathrm{~V}
\end{array}
$$

The reduction process starts with the adsorption and activation of $\mathrm{CO}_{2}$ onto the surface of the catalyst to form ${ }^{*} \mathrm{HCOO}$ or ${ }^{*} \mathrm{COOH}$ intermediates (the atom with ${ }^{*}$ binds to the surface) (Fig. 2a). ${ }^{10}$ Further reduction of ${ }^{*} \mathrm{HCOO}$ forms formic, while ${ }^{*} \mathrm{COOH}$ is reduced to ${ }^{*} \mathrm{CO}$ adsorbed on the catalyst surface. If ${ }^{*} \mathrm{CO}$ weakly binds to the surface of the catalyst, it is desorbed to form the gas product. If ${ }^{*} \mathrm{CO}$ binds to the surface strongly enough, it can be further reduced to form hydrocarbon products through two main paths. The first one involves a series of proton-coupled electron transfers, which lead to the formation of methanol and

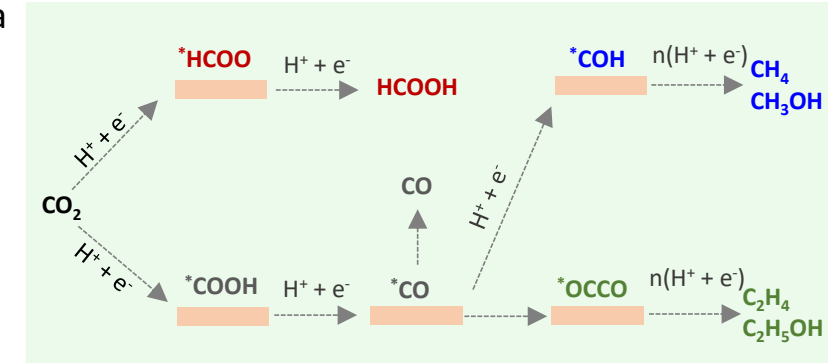

b

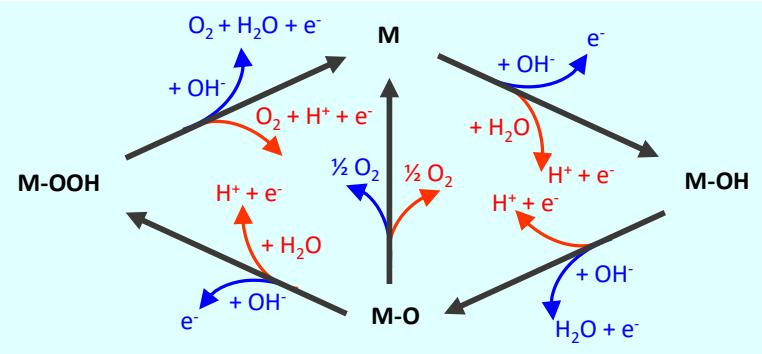

Fig. 2. a) Different pathways for $\mathrm{ECR}$ products including $\mathrm{HCOOH}, \mathrm{CO}, \mathrm{CH}_{4}, \mathrm{CH}_{3} \mathrm{OH}, \mathrm{C}_{2} \mathrm{H}_{4}$ and $\mathrm{C}_{2} \mathrm{H}_{5} \mathrm{OH}$; the ${ }^{*}$ label indicates the atom bound to the surface of the catalyst. b) Schematic illustration of the OER reaction pathways in alkaline media (blue arrows) and in acidic and neutral media (red arrows) (M: metal).

methane. The second path starts with preferential dimerization of ${ }^{*} \mathrm{CO}$ to form ${ }^{*} \mathrm{CO}$ dimers, which are further hydrogenated to form $\mathrm{C}_{2+}$ products such as ethylene and ethanol (Fig. 2a). ${ }^{10}$ The complex reaction pathways of ECR, which involve multiple proton-coupled electron transfers and various intermediates, making it difficult to control product selectivity. To achieve high selectivity, fine-tuning the adsorption energies of the intermediates is required, which can be accomplished via catalyst design and control of the reaction environment.

The performance of the $\mathrm{CO}_{2}$ reduction at the cathode is governed by two main factors: the local reaction environment and the catalyst. ${ }^{11}$ The local environment, such as $\mathrm{pH}$ and the identities of the ions and molecules on the surface of the catalyst, greatly affects the interaction of the reactants and intermediates in ECR and thus influencing the reaction pathway. For example, both theoretical calculations and experimental results have shown that the reduction of $\mathrm{CO}_{2}$ to methane involves multiple proton-coupled electron transfer processes; thus, a high $\mathrm{pH}$ negatively affects this reaction. In contrast, the reduction of $\mathrm{CO}_{2}$ to $\mathrm{C}_{2+}$ products, such as ethylene and ethanol, includes a rate-limiting ${ }^{*} \mathrm{CO}$ coupling reaction, which is $\mathrm{pH}$ independent because of the absence of protons involved. 4,10 Thus, increasing $\mathrm{pH}$ has been found to be an effective way to improve the efficiency of $\mathrm{CO}_{2}$ reduction to multiple carbon products as this suppresses the formation of methane without affecting the ${ }^{*} \mathrm{CO}$ dimerization. As the surface of the ECR catalyst is negatively charged, cations can easily adsorb on the catalyst surface during the reaction and influence the reaction mechanism. It has been suggested that large hydrated cations, including $\mathrm{K}^{+}$and $\mathrm{Cs}^{+}$exhibiting strong buffering properties, can lower the $\mathrm{pH}$ near the catalyst surface. Thus, they minimize the conversion of $\mathrm{CO}_{2}$ to carbonate and enable a high $\mathrm{CO}_{2}$ local 
concentration and reduce polarization losses, which preferentially enhance the selectivity toward $\mathrm{C}_{2+}$ products. ${ }^{12}$

Catalyst surface is where the reduction of $\mathrm{CO}_{2}$ occurs. ${ }^{13}$ The electronic and surface structures of catalysts, which are governed by their composition and morphology, determine the reaction pathways, and therefore their activity and selectivity. For example, Ag- and Au-based catalysts are efficient for $\mathrm{CO}$ production, whereas selective reduction of $\mathrm{CO}_{2}$ to formic acid (formate in basic condition) can be achieved using $\mathrm{Pd}, \mathrm{Sn}, \mathrm{Bi}$, and $\mathrm{Pb}$-based catalysts. ${ }^{5} \mathrm{Cu}$ is the only metal that can produce a wide range of products, including hydrocarbons and oxygenated products beyond $C_{1}$ due to its optimal $\mathrm{CO}$ binding energy. ${ }^{4}$ Several strategies such as alloying, hybridizing, controlling the sizes and shapes have been used to improve the performance of catalysts for ECR. Details about these approaches have been discussed in several reviews and are not the focus of the current paper. 4, 5,11,13 We will, however, discuss the catalyst layer of the GDE in more detail in the following section

\subsubsection{Anodic reactions}

The anode is the positive terminal in the $\mathrm{CO}_{2}$ electrolyzer, where oxygen evolution reaction (OER) $\left(2 \mathrm{H}_{2} \mathrm{O} \rightarrow \mathrm{O}_{2}+4 \mathrm{H}^{+}+4 \mathrm{e}^{-}\right.$, $\mathrm{E}^{\circ}=$ $1.23 \mathrm{~V}$ vs. $\mathrm{RHE}$ ) occurs to provide electrons that move to the cathode side to reduce $\mathrm{CO}_{2}$ to chemicals. The anode side does not affect the selectivity of the $\mathrm{CO}_{2}$ reduction process; however, its slow reaction kinetic increases the overall cell voltage, leading to low overall energy efficiency. ${ }^{13}$ Catalysts such as metal oxides are often used to lower the activation energy barrier and accelerate the oxidation reaction. Depending on the reaction environment, this reaction can be categorized into three different types, including alkaline, neutral, and acidic OER.

In alkaline media, the reactants for OER are hydroxide anions $\left(\mathrm{OH}^{-}\right)$and reaction often occurs with the first step being the formation of the $\mathrm{M}-\mathrm{OH}$ (M: metal) via 1-electron oxidation of $\mathrm{OH}^{-}$adsorbed on the metal site (Fig. 2b). ${ }^{13,14}$ The $\mathrm{M}-\mathrm{OH}$ is then transformed into $\mathrm{M}-\mathrm{O}$ after the addition of an $\mathrm{OH}^{-}$and the removal of a water molecule and an electron. The $\mathrm{M}-\mathrm{O}$ species can combine with another $\mathrm{M}-\mathrm{O}$ to generate an $\mathrm{O}_{2}$ molecule and two $\mathrm{M}$ active sites. They can also be converted into $\mathrm{M}-\mathrm{OOH}$ by adding an $\mathrm{OH}^{-}$while removing one electron. The addition of another $\mathrm{OH}^{-}$and the removal of an electron from $\mathrm{M}-\mathrm{OOH}$ lead to the generation of $\mathrm{O}_{2}$, a molecule of water, and the $\mathrm{M}$ active site (Fig. 2b). ${ }^{13}$ An effective catalyst should offer active sites on the surface to form the intermediates $(\mathrm{M}-\mathrm{OH}, \mathrm{M}-\mathrm{O}, \mathrm{M}-\mathrm{OOH})$, and facilitate the charge transfer with the electrode. Currently, mixed metal oxide/hydroxide such as $\mathrm{NiFe}^{15}$ and FeWCo oxyhydroxide $^{14}$ are among the best alkaline OER catalysts, exhibiting an overpotential of $200-300 \mathrm{mV}$ at a current density up to $500 \mathrm{~mA} / \mathrm{cm}^{2}$. In gas-phase ECR using an alkaline environment, OER catalysts are often deposited on a porous metal foam, i.e., Nickel, to maximize the total active area, reducing the required overpotential.

In neutral and acidic media, the reactants for OER are water molecules (Fig. 2b). Most active catalysts based on transition metal oxides such as $\mathrm{Ni}, \mathrm{Fe}$, Co are not stable during the OER process in neutral and acidic environments. Recent advances in neutral OER for ECR have been made ${ }^{16}$, but only at low current densities. At elevated current densities, the water oxidation produces a large number of protons on the surface of the catalyst, significantly decreasing the $\mathrm{pH}$, which leads to the corrosion of the electrode. Thus, most of the gas-phase ECR operating under neutral conditions are still based on $\mathrm{IrO}_{2}$, a commercial OER catalyst which is stable in both acidic and neutral environments. ${ }^{17,} 18$

While developing active and stable non-noble metal OER catalysts for neutral and acidic media is an important but challenging task for practical ECR, taking the advantages of advances in acid OER made for polymer electrolyte membrane electrolysis would accelerate the development of ECR technology. However, specific challenges related to the chemistry of ECR should also be addressed. In polymer electrolyte membrane electrolysis, the $\mathrm{IrO}_{2} \mathrm{OER}$ catalyst is usually mixed with an ionomer, i.e., Nafion, before being coated on a conductive support, predominantly porous titanium fiber. While this configuration works well as anode for the production of $\mathrm{CO}^{19}$ it is not stable for the production of alcohols. ${ }^{17,}{ }^{18} \mathrm{~A}$ possible reason would be the diffusion of alcohol products from cathode to the anode which can re-disperse the ionomer binder, leading to the redispersion of the catalyst nanoparticles. One approach to overcome this problem is to deposit $\mathrm{IrO}_{2}$ directly on the Ti support via a thermal treatment process. ${ }^{20}$ This approach improves the stability of the catalyst, but it comes with a cost of the total active surface area. Further studies on the deposition of $\mathrm{IrO}_{2}$ catalysts on porous $\mathrm{Ti}$ for ECR is recommended.

\subsubsection{Membrane}

Membranes are typically composed of a polymer backbone onto which fixed ionic sites are tethered via side-chains (Fig. 3a). Its primary role is to separate the anode and cathode while allowing exchanging ions between them. Efficient membranes require high ion conductivity and high chemical and mechanical stability. Currently, membranes used in ECR are developed primarily for water electrolyzers and fuel cells. Compared to water electrolysis, ECR generates several gas and liquid products, which may affect the performance of the membrane. The presence of carbonate anions and metal cations in the electrolytes further complicates the ion transport through the membrane during the $\mathrm{CO}_{2}$ conversion process. ${ }^{21}$

Three main types of membranes are currently employed in ECR, including anion-exchange, cation-exchange, and bipolar membranes (BPMs), which transport anions (e.g., $\mathrm{OH}^{-}$), cations (e.g., $\mathrm{H}^{+}$), and both cations and anions, respectively. The synthesis of anionic-exchange membranes (AEMs) often involves creating fixed cationic groups, such as ammonium or phosphonium and then treating the polymer with $\mathrm{KOH}$ to yield a hydroxide ion-conducting material. On the contrary, for cation-exchange membranes (CEMs), the negatively charged groups such as phosphate, sulfonate, or carboxylate are grafted on the backbone of the membrane, which allows cations to pass through. The BPM comprises a cation exchange layer laminated with an anion exchange layer. For AEMs, polysulfones and fluorinated polymers such as poly(vinylidene fluoride) are 
a
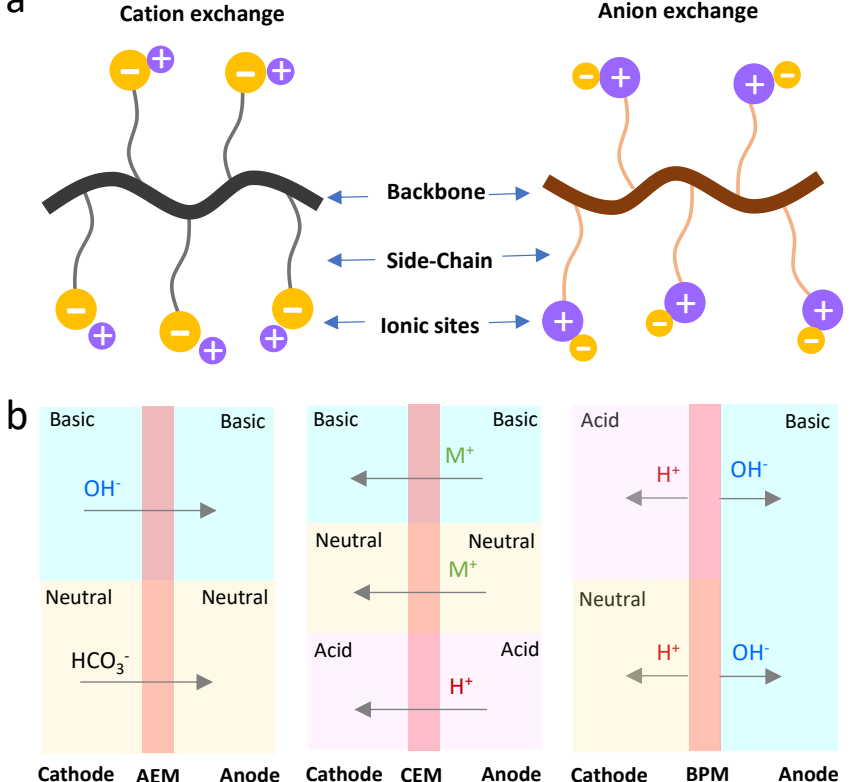

Fig. 3. a) Illustration of the structure of polymers used as cation- and anion-exchange membranes. b) Schematic illustration of the ion transport through different membranes (AEM, CEM, and BPM) and electrolyte environments (acidic, basic, and neutral). The arrows indicate the movement direction of the ions.

commonly employed, while the commercial Nafion (consisting of a hydrophobic fluorocarbon backbone $-\left[\mathrm{CF}_{2}-\mathrm{CF}_{2}\right]-$ with sulfonic groups) and Ultrex (containing polystyrene and a divinylbenzene cross-link structure grafted with sulfonic groups) are frequently used as CEMs.

The selection of the membrane for ECR is based on the target products and the reaction environment. Currently, AEMs are the most commonly used membranes in gas-phase ECR because they can be used efficiently in both neutral and basic media, which work best for ECR. $7,18,22$ During the reaction, the $\mathrm{OH}^{-}$or (bi)carbonate ions generated as by-products from the $\mathrm{CO}_{2}$ reduction at the cathode migrate to the anode side, where they eventually react with $\mathrm{H}^{+}$generated from OER (Fig. 3b). CEMs transport $\mathrm{H}^{+}$or other cations from anode to cathode during the reaction (Fig. 3b). The migration of $\mathrm{H}^{+}$lowers the $\mathrm{pH}$ on the surface of the catalyst, accelerating the competing hydrogen evolution reaction. The transport of metal cations from anode to cathode causes a gradient of metal cations between the two electrodes. The depletion of metal cations in anolyte may increase cell resistance and cell voltage. In case the target products are compounds such as formic and acetic, CEMs can be used because these products can balance the metal cations and form corresponding metal salts (formate and acetate). BPMs have been recently employed for gas-phase ECR because they enable the cathode and anode to operate at different pHs and minimize the products crossover (Fig. 3b). ${ }^{6,23}$ During the reaction, the water molecules are split into $\mathrm{OH}^{-}$and $\mathrm{H}^{+}$in the membranes which migrate to anode and cathode, respectively. Thus, the anode can be operated in an alkaline medium, which favors the kinetics of the OER. However, the $\mathrm{H}^{+}$ migrating to the cathode side lowers the $\mathrm{pH}$ and affects the $\mathrm{CO}_{2}$ reduction selectivity. Therefore, BPMs require a buffer layer, such as $\mathrm{NaHCO}_{3}$ and $\mathrm{KHCO}_{3}$, on the surface of the catalyst to be efficient for ECR. ${ }^{6,23}$

To enhance the performance of the electrolyzers, further increases in the ionic conductivity, especially for carbonate and bicarbonate ions, of the membrane are needed. Expanding of ion exchange sites should be avoided because it would induce more water uptake and swelling, decreasing the mechanical stability of the membrane. Therefore, it is necessary to optimize the location, type, and density of the ion-conducting groups while allowing the protection of the polymer backbone in the hydrophobic region. Moreover, creating ionic channels within the material to improve the ion mobility further is also an enticing strategy. Another approach to concurrently improve both the conductivity and stability of the membrane is to blend the polymer matrix with nanofillers such as metal ions and oxides, silica, graphene oxide, and carbon nanotubes. The mixed matrix membranes formed through this method can have their composition finely tuned to achieve optimized properties.

\subsection{Electrochemical cell designs}

The gas-phase electrolyzers can be divided into two main configurations: flow cell and membrane electrode assembly (MEA) cell. The main difference between the two configurations is the presence of a liquid electrolyte flow between the catalyst and membrane on the cathode side of the flow-cell. In this section, we highlight the key features, advantages, and limitations of each type.

\subsubsection{Flow cell}

Flow-cell reactors for ECR include current collectors for both anode and cathode, chambers for electrolytes, GDEs, and a membrane (Fig. 4a). The current collectors are also designed as the chambers for $\mathrm{CO}_{2}$ flowing in and out on the cathode side, and for anolyte and $\mathrm{O}_{2}$ releasing on the anode side. GDEs are often used for the cathode, while either GDE or catalyst supported on a hydrophilic substrate can be used for the anode side. An ion-exchange membrane is often used to separate the catholyte and anolyte chambers. In some cases, such as in a microfluidic flow cell configuration, the membrane is not needed. The back (gas diffusion layer side) of the cathodic GDE is pressed against the current collector while the front side (catalyst side) faces the membrane. On the anode side, the catalyst is located as close to the membrane as possible to reduce the Ohmic drop.

During the reaction, $\mathrm{CO}_{2}$ is fed in the gas phase, and a flow of liquid electrolyte is pumped through the catholyte chamber located between the catalyst layer and the membrane. The gas products are diffused back to the $\mathrm{CO}_{2}$ gas phase while the liquid products enter the liquid electrolyte. The presence of the electrolyte in flow cells allows for fine-tuning the reaction environment on the surface of the catalyst to achieve high $\mathrm{CO}_{2}$ conversion efficiency. ${ }^{7}$ 24-27 The $\mathrm{pH}$ and identity of the ions in the aqueous electrolyte are important parameters that influence the reaction on the cathode. For instance, the effect of $\mathrm{pH}$ can be observed when $\mathrm{OH}^{-}$ions adsorbed on or proximate to metal catalysts modulate the active sites, lowering the 

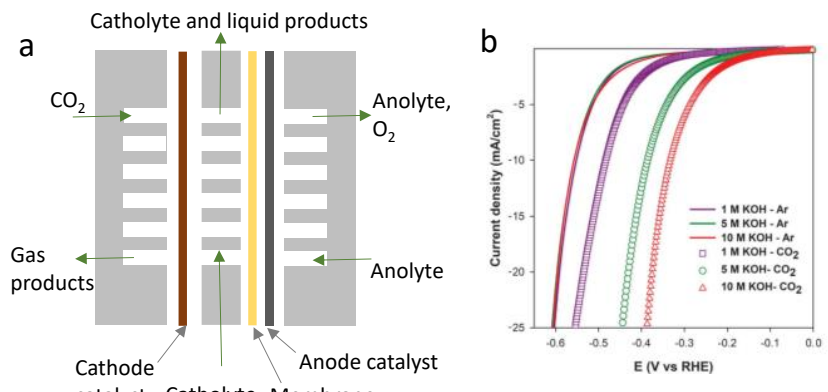

catalyst Catholyte Membrane

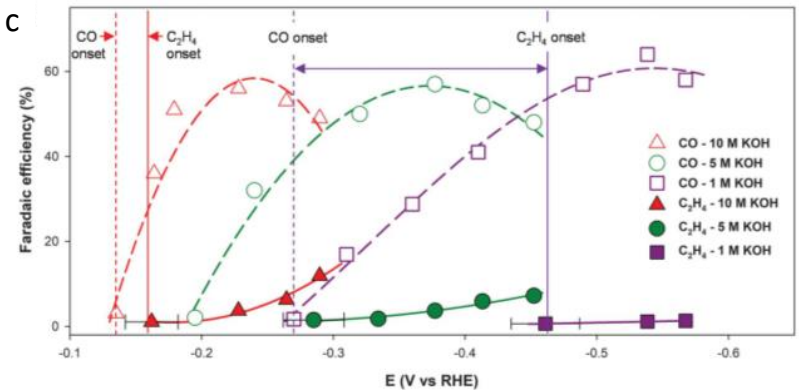

Fig. 4. a) Schematic illustration of a flow cell. b) Linear sweep voltammetry scan in various $\mathrm{KOH}$ electrolyte concentrations showing low overpotential $\mathrm{CO}_{2}$ reduction in high $\mathrm{KOH}$ concentrations (E: electrode potential). (c) $\mathrm{C}_{2} \mathrm{H}_{4}$ and $\mathrm{CO}$ Faradaic efficiencies showing the reduction of $\mathrm{C}_{2} \mathrm{H}_{4}$ onset potential with increasing $\mathrm{KOH}$ concentrations. Reproduced from ref. ${ }^{7}$ with permission from AAAS, copyright 2018.

reduction energy barriers for ethylene formation from $\mathrm{CO}_{2}$. It also lowers the adsorbed hydrogen atom coverage on the catalyst's surface, suppressing the competing hydrogen evolution reaction. ${ }^{7}$ Moreover, the high ionic conductivity of the hydroxide electrolytes, e.g., $\mathrm{KOH}, \mathrm{NaOH}$, compared to that of the $\mathrm{pH}$-neutral electrolytes, e.g., $\mathrm{KHCO}_{3}$, reduces ohmic losses and increases the overall energy efficiency of the system. It is found that the onset potential for $\mathrm{CO}_{2}$ reduction is significantly reduced with increasing $\mathrm{KOH}$ electrolyte concentration (Fig. 4b). ${ }^{7}$ The $\mathrm{CO}_{2}$ reduction to ethylene on $\mathrm{Cu}$ catalyst in $10 \mathrm{M}$ and $1 \mathrm{M} \mathrm{KOH}$ exhibited the onset potentials at around $-0.16 \mathrm{~V}$ and $-0.46 \mathrm{~V}$ vs. $\mathrm{RHE}$, respectively. The high $\mathrm{OH}^{-}$ concentration on the surface of the catalyst allows carbon monoxide and ethylene to form at similarly low potentials (Fig. 2c), thus significantly increasing the energy efficiency for the conversion of $\mathrm{CO}_{2}$ to ethylene. ${ }^{7}$ The alkaline flow-cell system allows $\mathrm{CO}_{2}$ conversion with high selectivity at high current densities; however, the formation of carbonate from the reaction of $\mathrm{CO}_{2}$ and $\mathrm{OH}^{-}$requires an additional electrolyte regeneration process, which can lower the overall energy efficiency.

While having a liquid electrolyte can be beneficial to controlling the reaction environment, it is also a source of instability in the system due to the potential penetration of liquid electrolyte into the $\mathrm{GDE}$, i.e., flooding. This greatly reduces $\mathrm{CO}_{2}$ diffusion to the catalyst and decreases the performance of ECR systems. The presence of a layer of liquid electrolyte also increases the overall cell resistance, leading to large total cell voltages at high current densities. Nevertheless, with its capability of fine-tuning the local reaction on the surface of the catalyst, the flow cell system remains a great platform for fundamental studies of ECR at industrially relevant current densities.

\subsubsection{Membrane electrode assembly cell}

In MEA cells, the porous cathode GDE and anode catalyst are pressed on both sides of a membrane, allowing for reducing the ohmic resistance caused by the electrolytes between the two electrodes (Fig. 4a). In this configuration, no liquid electrolyte is needed for the cathode side as the water reactant is provided through a vapor phase or water diffusion from the anode. The elimination of the catholyte minimizes the GDE flooding, thereby improving the system stability. ${ }^{17,} 18$ It also avoids impurities from the liquid electrolyte, which can potentially deactivate the catalysts. Unlike the flow cell where the liquid products are diluted in the electrolyte, parts of the liquid products exit the MEA reactor from the gas phase together with the gas and water vapor, allowing the production of liquid products with high concentrations by condensing gas mixture of the outlet. ${ }^{18}$

In ECR systems, the migration of ions and the diffusion of molecules between the two electrodes influence both the energy efficiency and the subsequent product separation process. The flexible architecture of MEAs allows one to control these processes by reconfiguring their membranes. For example, instead of using one type of membrane, multiple membranes in combination with solid polymer electrolytes can be used, as demonstrated by Xia et al. ${ }^{28}$ In their configuration, the GDE is pressed against an AEM while the anode is in contact with a CEM. The two electrodes are separated by a solid polymer electrolyte. During the reaction, the anionic products migrate from the cathode to the solid electrolyte chamber while the metal cations (or protons) migrate in the opposite direction from the anode (Fig. $\mathbf{5 b}$ ), producing pure products in the solid electrolyte layer. This cell configuration also allows continuous production of pure products for up to 100 hours, indicating its potential for practical applications (Fig. 5 c)..$^{28}$
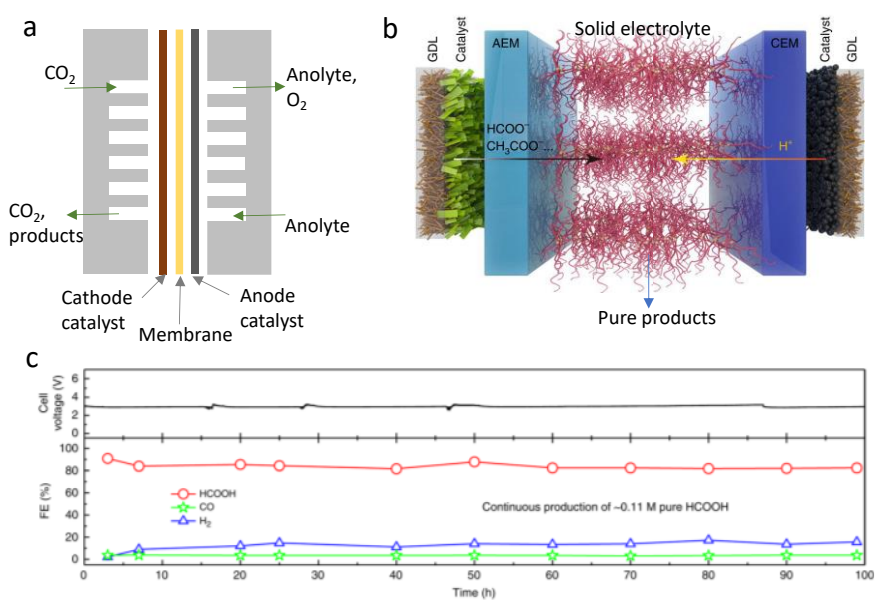

Fig. 5. Schematic illustration of a zero-gap cell (a), and a cell with solid electrolyte (b). Long-term operation test of $\mathrm{CO}_{2}$ reduction to pure $\mathrm{HCOOH}$ solution (c), showing high selectivity and stability of the $2 \mathrm{D}-\mathrm{Bi}$ catalyst at $30 \mathrm{~mA} / \mathrm{cm}^{2}$. The Faradaic efficiency of $\mathrm{HCOOH}$ is maintained at more than $80 \%$ over the 100 hours continuous operation. Reproduced from ref. ${ }^{28}$ with permission from Nature Publishing Group, copyright 2019. 
From the architecture aspect, MEAs resemble the commercially existing polymer electrolyte membrane fuel-cells and electrolyzers, allowing them to be readily integrated into these matured technologies. ${ }^{29}$ However, because the chemistry of ECR is different from those of fuel cells and water electrolyzers, several design parameters in MEAs for ECR need to be considered. First, in the MEA system, the carbonate ions, formed from $\mathrm{CO}_{2}$ during the reaction, migrate to the anode where they react with $\mathrm{H}^{+}$and are converted back to $\mathrm{CO}_{2}$. Thus, a mixture of $\mathrm{CO}_{2}$ and $\mathrm{O}_{2}$ gas is produced at the anode, which requires additional separation step to reuse $\mathrm{CO}_{2}$. Second, the high concentration of liquid products at the catalyst-membrane interface result in product-crossover through the membrane, ${ }^{30}$ leading to the dilution of the products in the anolyte and possible re-oxidation back to $\mathrm{CO}_{2}$ at the anode. Highconcentration alcohols can also lower the stability of the membranes.

The lack of liquid catholyte between electrode and membrane in MEAs requires additional considerations for electrode design. Because the local environment significantly affects the $\mathrm{CO}_{2}$ electroreduction, designing electrodes with the capacity of tailoring the local environment is critical. The electrode-membrane interface in MEA governs the ion transport between the two electrodes. Enabling an intimate contact between the electrode and membrane is crucial for high ion mobility. This can be achieved via two main approaches: (1) direct depositing the catalyst on the membrane; and (2) depositing the catalyst on a GDL followed by hot-pressing to the membrane to form MEA. While both approaches are widely used in MEA for fuel-cell and water electrolyzer applications, the second approach is currently dominant in the MEA for ECR because it provides greater flexibility in catalyst layer design. Unlike the catalysts for fuel-cells and water electrolyzers in which maximizing the active surface area is the major focus, the activity and selectivity of ECR are strongly dependent on the overall morphology of the catalyst layer. The current lack of robust and efficient membranes for ECR further limits the approaches for MEA fabrication.

\section{Gas diffusion electrode}

The GDE distinguishes gas-phase ECRs from the aqueous phase ones. It consists of a catalyst layer deposited on a porous GDL (Fig. 6a), which significantly reduces the $\mathrm{CO}_{2}$ diffusion pathway $(\sim 50 \mathrm{~nm})$ to the catalyst surface compared to that of common planar electrodes used in $\mathrm{H}$-cells $(\sim 50 \mu \mathrm{m}) .{ }^{31}$ Thus, the GDE maintains a high $\mathrm{CO}_{2}$ concentration near the catalyst surface for high current density operations, even in an alkaline electrolyte, which could not be achieved in aqueous systems. ${ }^{7,24}$

\subsection{Gas diffusion layer}

The GDL is a hydrophobic, porous, and conductive structure consisting of two layers: a macroporous substrate (MPS) and a microporous layer (MPL). Previous studies on GDEs for ECR mainly used carbon-based GDL. ${ }^{32}$ The GDL transports the reactants and products between the catalyst layer and the flow- a
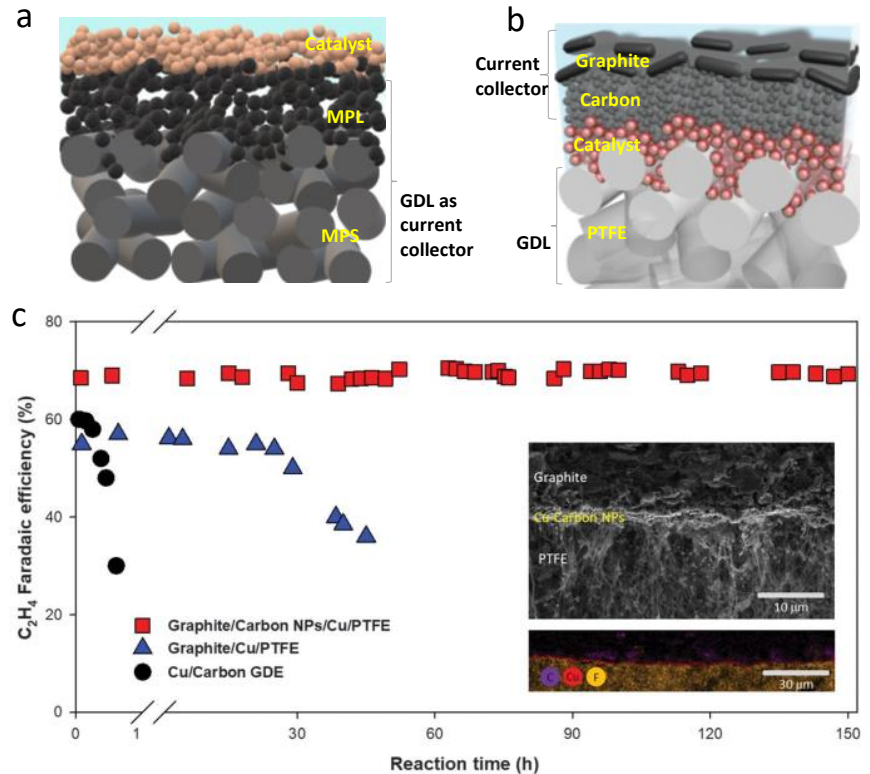

Fig. 6. Schematic illustration of the structure of a conventional carbon-based gas diffusion electrode (a) and the graphite/carbon nanoparticles/Cu/PTFE electrode (b) ${ }^{7}$. Long-term performance test of $\mathrm{CO}_{2}$ reduction to ethylene in $7 \mathrm{M} \mathrm{KOH}(\mathrm{c})$, showing high selectivity and stability of the graphite/carbon nanoparticles/Cu/PTFE electrode compared with that of a traditional carbon-based gas diffusion electrode. Insets show the cross-section SEM and energy-dispersive X-ray spectroscopy mapping of the sample after 150 hours of continuous $\mathrm{CO}_{2}$ reduction operation. The stability test was performed at a constant applied voltage of $-0.55 \mathrm{~V}$ vs. RHE. Reproduced from ref. ${ }^{7}$ with permission from AAAS, copyright 2018.

field channel while exchanging electrons between them. The MPS provides mechanical stability and electrical contact for the $\mathrm{GDE}$, as well as distribute $\mathrm{CO}_{2}$ gas through its macro-scale pores. This substrate is usually made of conductive carbon fibers or titanium foam. The porosity, hydrophobicity, and thickness of MPS can be tailored depending on the applications or reaction conditions. The hydrophobicity of the MPS is often enhanced by coating it with a fluorinated polymer, such as polytetrafluoroethylene (PTFE). The loading of PTFE on carbonbased MPS is in the range of 5-20 wt.\%. Usually, a high PTFE loading is desired for ECR application; however, it needs to be optimized because excessive loading results in a significant decrease in GDL electrical conductivity and blockage of the GDL pores.

The MPL, located between the MPS and the catalyst layer, is added to GDE to enhance the interfacial electrical connection and to prevent flooding in GDE. The MPL is commonly composed of a mixture of carbon black nanoparticles and a hydrophobic polymer, e.g., PTFE. Its hydrophobic nature and nanosize pores allow the transportation of gas molecules while blocking the penetration of liquid water. To form MPL, carbon black nanoparticles are mixed with PTFE colloids in a mixture of alcohol and water to form an ink, which is then coated on the MPS using a blade coating technique (details about this technique is discussed in the following section). The substrate is subsequently heated to the melting point of PTFE to remove all organic surfactant impurities and to improve the hydrophobicity of the GDL. Notably, the MPL is not merely attached to the MPS. Since the size of the carbon nanoparticles 
is much smaller than the pore size of the substrate $(>10 \mu \mathrm{m})$, some nanoparticles can enter the pores and form an intermediate zone, of which the thickness is governed by the viscosity of the ink mixture. The compression of the MPL on MPS can further force the MPL to penetrate the MPS, which improves the cohesion and the compactness of the GDL. The morphology, porosity, thickness, and hydrophobicity of the MPL are very important for ECR because of its complex gas and liquid transport. These properties can be tuned by tailoring its composition, i.e., the ratio between carbon nanoparticles and PTFE, and processing conditions. Several types of MPLs with different morphologies and hydrophobicity have been developed for fuel cells and electrolyzers. However, most of them are not suitable for $\mathrm{CO}_{2}$ electroreduction, degrading rapidly under ECR conditions at high current density, especially when liquid products such as ethanol and propanol are produced. $7,33,34$

Low stability is an issue preventing carbon-based GDLs from practical ECR applications. At high current densities and in basic media, the surface of carbon gradually turns from hydrophobic to hydrophilic, leading to the flooding of the GDE after a few hours of operation. ${ }^{7}$ One way to overcome this problem is to functionalize commercial carbon-based GDLs with hydrophobic compounds, such as fluoroalkyl silane, to improve their stability. ${ }^{34}$ Using this approach, a long-term operation of 40 hours at a current density of $400 \mathrm{~mA} / \mathrm{cm}^{2}$ for producing ethylene and ethanol has been achieved. ${ }^{34}$ Another approach is to use non-carbon-based GDLs, such as porous PTFE filters which are composed of a polypropylene backing layer and a porous PTFE fiber with a diameter ranging from 0.1 to $3 \mu \mathrm{m} .7,17$, $24,27,35$ This porous PTFE layer is chemically stable, enabling ECR in the harsh environment i.e., highly alkaline electrolytes. Because PTFE is not electrically conductive, a layer of carbon and graphite was added on the top of the catalyst layer to improve its conductivity (Fig. 6b). In this configuration (graphite/carbon nanoparticles/Cu/PTFE electrode), the hydrophobicity and electrical conductivity requirements of the MPL are decoupled. The pure hydrophobic PTFE layer prevents flooding while the carbon nanoparticles and graphite stabilizes the $\mathrm{Cu}$ catalyst surface. In a flow cell configuration, this PEFEbased GDL operated for 150 hours without a loss in ethylene selectivity at current densities between 75 and $100 \mathrm{~mA} / \mathrm{cm}^{2}$ (Fig. 6c). ${ }^{7}$ In a MEA cell, the PTFE-based GDE was also stable, maintaining a current density above $100 \mathrm{~mA} / \mathrm{cm}^{2}$ for more than 100 hours with good selectivity for ethylene and ethanol. ${ }^{18}$

Overall, GDL is an important component in GDE; however, it is currently overlooked because of the availability of a variety of commercial GDLs for fuel-cell application. It is worth noting that most of these GDLs tested so far are not stable for $\mathrm{CO}_{2}$ reduction, especially for ethylene and ethanol production. The creation of next-generation GDLs with mechanical and chemical properties suited for $\mathrm{CO}_{2}$ reduction is necessary to push the ECR research going forward.

\subsection{Catalyst layer}

In gas-phase ECR, high operating current densities lead to a significant change in the local environment, including $\mathrm{pH}$ and
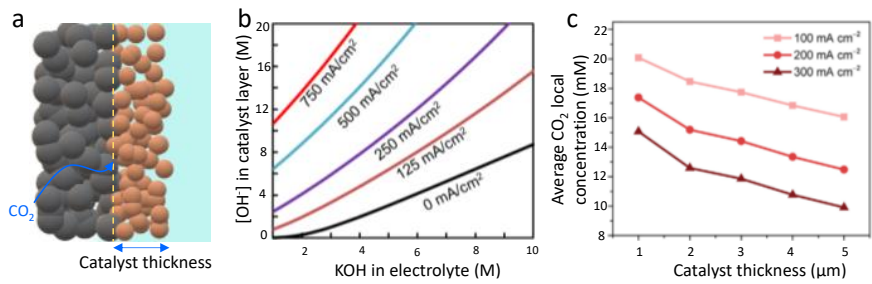

Fig. 7. a) Diffusion of $\mathrm{CO}_{2}$ to the catalyst layer. b) Predicted hydroxide concentration inside the catalyst layer over a broad current density and electrolyte concentration for a $100 \mathrm{~nm}$ thick catalyst. c) Average $\mathrm{CO}_{2}$ local concentration with different catalyst thicknesses at different current densities in $\mathrm{pH}$-neutral electrolyte. Reproduced from ref. $^{7}$ with permission from AAAS, copyright 2018 , and from ref. ${ }^{36}$ with permission from Elsevier, copyright 2020.

$\mathrm{CO}_{2}$ concentration, in the catalyst layer. ${ }^{31}$ The performance of the catalyst layer is governed not only by the morphology and composition of the active catalyst particles but also by its overall structures. Three main catalyst layer structures in GDE include two dimensional (2D) thin film, three dimensional (3D) nanostructures; and 3D nanoparticulate layer.

\subsubsection{Local $\mathrm{pH}$ and $\mathrm{CO}_{2}$ gradient in catalyst layer}

During $\mathrm{CO}_{2}$ reduction, $\mathrm{CO}_{2}$ combines with protons from water molecules to produce targeted products and $\mathrm{OH}^{-}$as a byproduct. These $\mathrm{OH}^{-}$ions increase the local $\mathrm{pH}$ and react with $\mathrm{CO}_{2}$ molecules dissolved in the electrolyte to generate bicarbonate $\left(\mathrm{HCO}_{3}{ }^{-}\right)$and carbonate $\left(\mathrm{CO}_{3}{ }^{2-}\right)$, significantly reducing the $\mathrm{CO}_{2}$ availability. The concentration of $\mathrm{OH}$ - in the catalyst layer is dependent on the nature of the electrolyte and the operating current density. ${ }^{31}$ Electrolyte with a strong buffering capacity

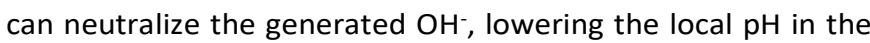
catalyst layer. However, when an alkaline electrolyte is used, the $\mathrm{OH}^{-}$concentration increases rapidly with increasing current density (Fig. 7a and b). Modeling results showed that the $\mathrm{OH}^{-}$ concentration in the catalyst layer could be an order of magnitude higher than that in the bulk when the reaction operates at a current density of $750 \mathrm{~mA} / \mathrm{cm}^{2}$ in $1 \mathrm{M} \mathrm{KOH}$ electrolyte. ${ }^{7}$ Consequently, the $\mathrm{CO}_{2}$ concentration in the catalyst layer is also decayed with a high concentration near the catalyst-GDL interface and gradually depleted within the catalyst layer (Fig. 7c). ${ }^{36}$ Managing the local $\mathrm{pH}$ and $\mathrm{CO}_{2}$ reactant is, therefore, an important aspect in designing catalyst layers.

\subsubsection{D Thin-film catalyst layer}

2D thin-film catalysts consist of a continuous thin layer of active materials, with thickness often in the range of $10-500 \mathrm{~nm}$, on the surface of the GDL (Fig. 8a). The 2D structure enables a uniform $\mathrm{CO}_{2}$ reactant concentration and local reaction environment throughout the catalyst layer, which can enhance both the activity and selectivity. $7,17,30,35$

2D thin-film electrocatalysts for ECR are normally fabricated using physical deposition methods, 7, 25, 27, including evaporation deposition (thermal, sputtering, and electron-beam), and atomic layer deposition. Compared to the coating methods with ionomers for nanoparticles, the physical deposition methods provide a stronger catalyst-substrate interaction because the catalysts are directly grown on the substrate, leading to enhanced stability. Moreover, they enable the deposition of 


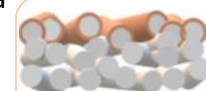
Composition
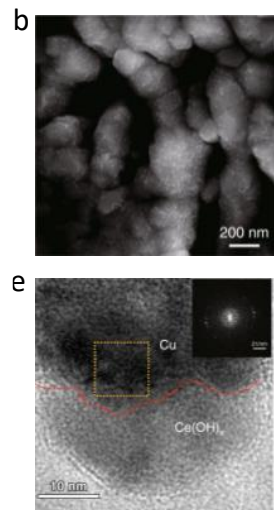

$\mathrm{h}$

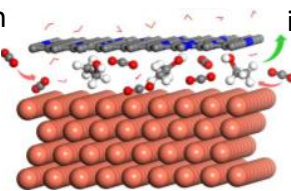

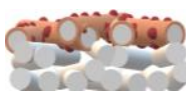

Hybrid
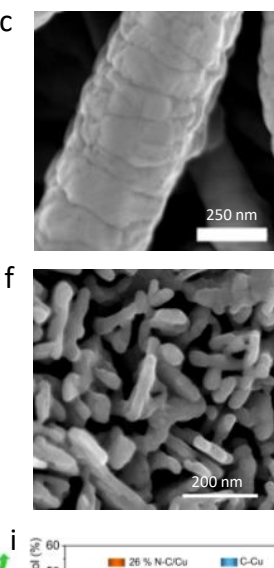

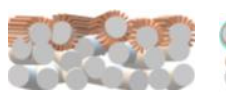

Morphology

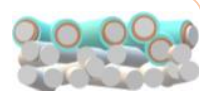

Core-shell

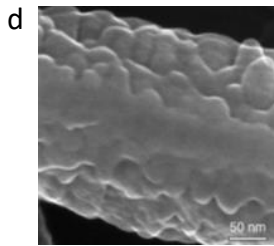

g

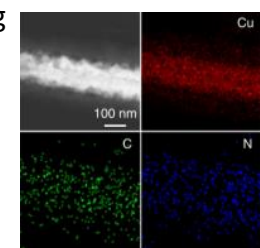

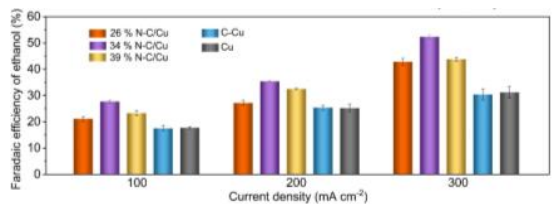

Fig. 8. a) Important factors for the fabrication of efficient thin-film catalyst layers. b) and e) SEM image and high-resolution TEM image of $\mathrm{Ce}(\mathrm{OH})_{x} / \mathrm{Cu} / \mathrm{PTFE}$, respectively. ${ }^{37}$ The red dashed line draws attention to the interface, and the inset shows the FFT pattern corresponding to the yellow square. c) and f) SEM images of Ag/PTFE and carbonatederived Ag/PTFE membranes, respectively. ${ }^{27} \mathrm{~d}$ ) and g) Secondary electron image (d) and the corresponding high-angle annular dark-field scanning transmission electron microscopy (HAADF-STEM) image, as well as the elemental mapping of $\mathrm{Cu}, \mathrm{N}$, and $\mathrm{C}$ taken from a section of one $34 \% \mathrm{~N}-\mathrm{C} / \mathrm{Cu} / \mathrm{PTFE}$ nanofiber $(\mathrm{g})$. $\mathrm{h}$ ) Illustration of $\mathrm{CO}_{2}$ intercalation at the $\mathrm{N}-\mathrm{C} / \mathrm{Cu}$ interface and the production of ethanol. i) The Faradaic efficiencies of ethanol on different catalysts under different current densities. ${ }^{30}$ Reproduced from ref. ${ }^{27}$ with permission from American Chemical Society, copyright 2018, and from refs. ${ }^{30,37}$ with permission from Nature Publishing Group, copyrights 2020 and 2019, respectively.

various types of materials, including metals, metal oxides, and metals sulfides, which can be used directly as the catalysts or as their precursors. Variation in catalyst composition can be achieved via co-deposition or sequential deposition approaches. In addition, physical deposition approaches can be combined with post-treatment methods, including ion exchange, surface reconstruction, and electrodeposition, to fine-tune the structure of the catalysts further.

To date, co-deposition is the most common method to fabricate 2D multi-component catalyst layers. ${ }^{38,} 39$ Using $\mathrm{Cu}$ and $\mathrm{Ag}$ targets and sputtering deposition, $\mathrm{Cu}-\mathrm{Ag}$ thin-film alloys, deposited on a PTFE gas diffusion layer, with $\mathrm{Cu}$ concentration varying from 70 to $90 \%$ was achieved. ${ }^{38}$ In this method, the two $\mathrm{Ag}$ and $\mathrm{Cu}$ targets are bombarded with an ion beam to eject their surface atoms that are eventually deposited on the PTFE substrate with uniform compositional distribution throughout the catalyst layer. With optimal composition, the $\mathrm{Cu}-\mathrm{Ag}$ catalyst $\left(\mathrm{Cu}_{0.86}-\mathrm{Ag}_{0.14}\right)$ exhibited an ethanol Faradaic efficiency of $41 \%$ at a current density of $250 \mathrm{~mA} / \mathrm{cm}^{2}$, which is much higher than that of the pure $\mathrm{Cu}$ electrode (ethanol Faradaic efficiency 29\%). In another work, Cu-Al alloy was successfully deposited on a GDL via thermal co-deposition. Etching of Al from the alloy using dilute acid $(\mathrm{HCl})$ resulted in a porous thin film with an optimal $\mathrm{Cu}$ : $\mathrm{Al}$ ratio. The designed $\mathrm{Cu}-\mathrm{Al}$ catalysts exhibited a very high ethylene selectivity of up to $80 \%$ at a current density of $400 \mathrm{~mA} / \mathrm{cm}^{2}{ }^{39}$ Another approach for the fabrication of thinfilm alloy electrocatalyst is the galvanic exchange, which has been successfully applied for deposition of alloy catalysts on a solid substrate for aqueous ECR. However, this method has not been widely employed for 2D thin-film catalysts in gas-phase ECR. In this approach, a physical deposition step can be used to fabricate a thin catalyst layer, followed by a galvanic exchange process to tune the composition. This could be an effective approach for the design of high-performance catalysts for gasphase ECR. To form a hybrid 2D nanostructured layer, posttreatment such as chemical/electrochemical modification can be used. ${ }^{37}$ For example, metal oxide/hydroxide of $\mathrm{Ce}$ and $\mathrm{Ni}$ can be electrodeposited on the surface of the pre-synthesized $\mathrm{Cu} /$ PTFE to form an oxide/Cu/PTFE hybrid catalyst (Fig. 8b and e). The presence of the oxide clusters on the surface of $\mathrm{Cu}$ was found to tune the adsorbed hydrogen, and thus shift the conversion of $\mathrm{CO}_{2}$ toward ethanol. ${ }^{37}$

To tune the morphology of $2 \mathrm{D}$ thin-film catalysts, one can control the evaporation parameters, including deposition rates and times. For example, Cu nanoparticles with size varying from 10 to $100 \mathrm{~nm}$ deposited on GDE can be achieved by controlling thermal evaporation time. ${ }^{7}$ However, both the particle size and the thickness of the catalyst layers simultaneously change, making it difficult to control the two parameters separately. Another approach is to reconstruct the surface of catalysts once they have been deposited on the GDL. For instance, metallic $\mathrm{Cu}$ deposited on a GDL can be used as a precursor to grow a $\mathrm{CuCl}$ thin film, which is subsequently converted to $\mathrm{Cu}_{2} \mathrm{O}$ and reconstructed $\mathrm{Cu}$ catalysts. ${ }^{25}$ This process tunes an irregular $\mathrm{Cu}$ catalyst into $\mathrm{Cu}$ cubes, which are active and selective for producing $\mathrm{C}_{2+}$. Electrochemical approaches can also be used to reconstruct a pre-deposited metal thin film. In this approach, the metallic layer deposited on GDL is electrochemically oxidized in an electrolyte to form the corresponding metal salt or oxide/hydroxide, which is subsequently electrochemically reduced to form the reconstructed catalyst. ${ }^{27}$ This oxidation/reduction approach enables the fabrication of thin catalyst layers with the exposure of the preferred facets and high grain boundary density, which are desirable for $\mathrm{CO}_{2}$ electroreduction (Fig. $\mathbf{8 c}$ and f).

In ECR, the reaction mechanism is highly sensitive to the environment on the surface of the catalyst, including the $\mathrm{pH}$, the nature of the ions, and the coordination of the reactants and intermediates. ${ }^{11}$ While controlling the composition of the electrolyte offers a way to tune the surface $\mathrm{pH}$ and adsorbed ions, fine-tuning the coordination of the intermediates requires precise control over the structures of the active sites. One way to achieve this goal is to confine the reaction space via surface catalyst coating. ${ }^{17}$ Thanks to the thin layer structure and the strong catalyst-substrate interaction, the 2D catalyst layer enables direct surface modifications of the catalyst deposited on the GDL, leading to a core-shell structure with precise control over the active site structure and local reaction environment. For example, when a thin film of $\mathrm{N}$-arylpyridinium was electrochemically coated on the surface of the Cu catalyst, it changes the local charge distribution and the adsorption of $\mathrm{CO}$ 
intermediates on the $\mathrm{Cu}$ surface, driving the reaction toward the formation of $\mathrm{C}_{2+}$ products. ${ }^{17}$ In a flow cell configuration with a pH-neutral electrolyte, the modified catalysts achieve maximum Faradaic efficiency of up to $72 \%$ at a current density of $300 \mathrm{~mA} / \mathrm{cm}^{2}$. The coating layer also enables the catalyst to work efficiently in a MEA cell, maintaining a high selectivity of $65 \%$ for 180 hours at around $125 \mathrm{~mA} / \mathrm{cm}^{2} .{ }^{17}$ The confinement in 2D nanostructured catalysts can also be achieved via sequential physical deposition. In this approach, target active materials are first deposited on the GDL, followed by another deposition of coating materials. For example, $\mathrm{N}$-doped carbon was deposited on the surface of a $\mathrm{Cu}$ /PTFE catalyst to form an $\mathrm{N}$-doped $\mathrm{C} / \mathrm{Cu}$ /PTFE structure (Fig. $\mathbf{8} \mathbf{d}, \mathbf{g}$, and $\mathbf{h}$ ). The composition and thickness of the $\mathrm{N}$-doped $\mathrm{C}$ can be controlled by changing the deposition conditions such as the deposition rate, time, and $\mathrm{N}_{2}$ gas flow rate. It is suggested that the presence of $\mathrm{N}$-doped carbon on the surface of $\mathrm{Cu}$ changes the reaction pathway by suppressing the formation of ethylene. As a result, the catalyst converts $\mathrm{CO}_{2}$ to ethanol with an impressive Faradaic efficiency of $52 \%$ at $300 \mathrm{~mA} / \mathrm{cm}^{2}$ current density in a flow cell (Fig. 8i). When tested in a MEA cell, the $\mathrm{N}$-doped $\mathrm{C} / \mathrm{Cu} / \mathrm{PTFE}$ catalysts also exhibited a high ethanol Faradaic efficiency of around $50 \%$. These results suggest that surface coating to produce catalysts with confined reaction space is an effective strategy to develop electrodes for MEA cell configuration.

In summary, 2D thin-film catalyst layers provide a great platform for the design of highly active and selective catalysts with well-control over the catalyst structure and local environment. We discussed here a few examples using the thermal evaporation technique; however, other methods such as atomic layer deposition, which has been successfully used to fabricate thin-film materials, can also be employed for fabricating 2D catalyst layers. Regardless of the deposition method, an efficient 2D catalyst layer should have a high degree of order, good adhesion to the GDL, uniformity of thickness, and homogeneity of the composition. While a relatively high current density (up to $400 \mathrm{~mA} / \mathrm{cm}^{2}$ ) and good stability have been achieved with 2D nanostructured layers, a combination with a 3D GDL with a high surface area would further improve their performance.

\subsubsection{D Nanostructured catalyst layer}

3D nanostructured catalysts for ECR involve a layer of wires, needles, or dendrites grown directly on the surface of the GDL (Fig. 9a-d). This catalyst structure has the advantage of high electrical conductivity because the catalyst is directly grown on the conductive substrate. Its high surface area-volume aspect ratio is of great interest for catalytic applications. In addition, the sharp tip feature, such as in a nanoneedle, can further enhance ECR via the electric field effect. ${ }^{40}$

Nanostructured catalysts are usually grown on a conductive substrate via an electrodeposition (electroplating) process. It involves the reduction of metallic ions from the electrolyte into metallic atoms on a cathode surface. For example, to deposit $\mathrm{Au}$ nanoneedles on a substrate, $\mathrm{HAuCl}_{4}$ is often used, with the $\mathrm{Au}^{3+}$ ions being reduced to $\mathrm{Au}^{0}$ during the electrodeposition (Fig. 9a). The morphology of the catalyst can be controlled by adjusting synthesis conditions, including applied voltage (or current), electrolyte composition, and deposition temperature and time. When highly negative potentials (high overpotentials) for electrodeposition are applied, the nucleation is significantly promoted. Additionally, at high current densities, the metal ions are consumed quickly, and dendritic structures are often obtained. With low overpotentials and low plating currents, the metal ions consumed are efficiently replenished via diffusion; hence the nanostructures tend to grow in all directions and exhibit more isotropic features. ${ }^{41}$ Using electrodeposition technique, dendrite structures of other metals, including $\mathrm{Zn}$ and Ag can also be fabricated (Fig. 9b). ${ }^{42}$ To grow highly-dense dendrite structures with macropores (Fig. 9c), a high growth rate at a relatively negative applied potential is needed. At that condition, hydrogen evolution occurs concurrently with the deposition of the metal. The hydrogen gas bubbles act as a template for the formation of macropores. ${ }^{43}$ Co-deposition can be used to achieve nanostructures of alloy catalysts; however, one should pay attention to the galvanic exchange between the formed metallic phase and the metallic ions in the precursor. Precise control over the precursor concentration and deposition rates is needed to achieve desired compositions and morphologies.

While the growth of 3D nanostructured catalysts on conductive substrates, predominantly metal foils, and hydrophilic carbon substrates, has been widely explored in aqueous ECR, the deposition of these catalysts on a GDL for gasphase ECR has been rarely reported. One challenge in the electrodeposition of a catalyst directly on a GDL comes from the hydrophobic surface of the GDL. Metal precursors are usually
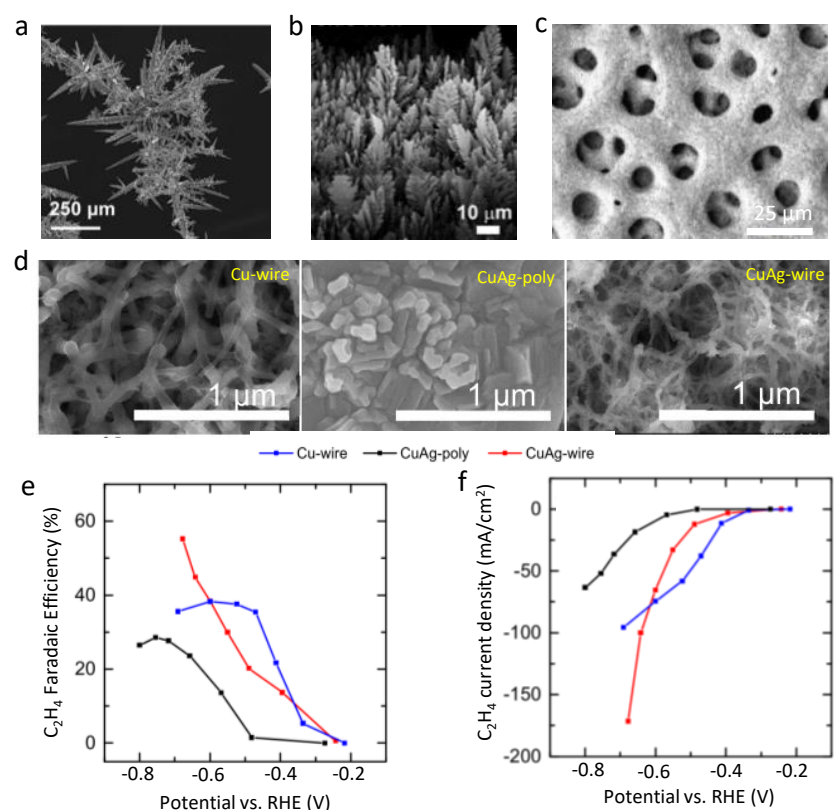

Fig. 9. a-d) SEM images of 3D structures catalyst: Au needles grown at $-200 \mathrm{mV}$ (a), a Zn dendrite catalyst (b), a Ag foam showing macropores (c), $\mathrm{Cu}$ wire electrodeposited with DAT, CuAg poly $(6 \% \mathrm{Ag})$ electrodeposited without DAT, and CuAg wire (6\% Ag) electrodeposited with DAT (d). DAT = 3,5-diamino-1,2,4-triazole. e) Faradaic efficiency and current density (normalized to the geometric area) for the electroreduction of $\mathrm{CO}_{2}$ to ethylene on the CuAg poly (black), $\mathrm{Cu}$ wire (blue), and $\mathrm{CuAg}$ wire (red) samples. Reproduced from refs. ${ }^{41-44}$ with permission from American Chemical Society, copyrights $2016,2015,2018$, and 2018, respectively. 
dissolved in a polar aqueous system that is incompatible with the hydrophobic nature of GDLs. To overcome this problem, GDLs are usually pre-treated with acids, e.g., a mixture of $\mathrm{H}_{2} \mathrm{SO}_{4}$ and $\mathrm{HNO}_{3}$, to form carboxyl, carbonyl, hydroxyl, and sulfate groups and provide the carbon surface with hydrophilicity. In this approach, however, one must be careful not to turn all the GDL into a hydrophilic material because it would lose its gas diffusion function and cause flooding during ECR. Another method is to coat the surface of the GDL with a thin layer of a targeted metal using a physical deposition method. ${ }^{35,} 44$ This thin metal layer plays roles as a binder and seeds for the growth of metallic nanostructures on GDL. For example, to grow $\mathrm{Cu}-\mathrm{Ag}$ wires on a carbon GDL, a $10-\mathrm{nm}$ thick $\mathrm{Cu}$ was first deposited using a thermal evaporation process. Using 3,5-diamino-1,2,4triazole as a structure-directing agent, nanowires of $\mathrm{Cu}$ or $\mathrm{Cu}$ $\mathrm{Ag}$ alloys with different $\mathrm{Ag}$ contents can be achieved via an electrochemical deposition process (Fig. 9d). When tested for ECR using a flow cell, $\mathrm{Cu}-\mathrm{Ag}$ exhibited much higher current density and selectivity toward ethylene and ethanol compared to those of pure $\mathrm{Cu}$ wire or $\mathrm{Cu}-\mathrm{Ag}$ nanoparticles. At optimal conditions, $\mathrm{Cu}-\mathrm{Ag}$ wires showed an ethylene Faradaic efficiency of $60 \%$ at a current partial density of $175 \mathrm{~mA} / \mathrm{cm}^{2}$ (Fig. 9e and f). It is suggested that the high active surface area and the presence of $\mathrm{Cu}_{2} \mathrm{O}$ oxide phase contribute to the high activity and selectivity of $\mathrm{Cu}-\mathrm{Ag}$ wire catalysts. ${ }^{44}$

The electrodeposition of catalysts on GDL can be performed either ex situ or in situ. In the ex situ method, the desired catalysts are optimized in a separate electrochemical system before they are used for ECR. This approach has the advantage of high freedom in optimizing the synthesis conditions because the metal precursors can be dissolved in many types of electrolytes. However, the surface of some catalysts, i.e., $\mathrm{Cu}$, which are sensitive to the air, can be altered before being tested for ECR. The in situ method involves the evolution of the catalysts on the electrode during $\mathrm{CO}_{2}$ reduction conditions, which can help overcome this problem. In this method, the metal precursors can be added to the electrolyte or preloaded on the GDL. For example, copper sulfate was added to a $\mathrm{KBr}$ electrolyte at a pH of 2.5 for the in situ growth of the $\mathrm{Cu}$ dendrite catalyst during ECR. ${ }^{45}$ At a current density of 170 $\mathrm{mA} / \mathrm{cm}^{2}, \mathrm{Cu}$ dendrites exhibited an ethylene Faradaic efficiency of $57 \%$ (Fig. 10a and b). Solid metal precursors can also be deposited on the electrode for the in situ growth of nanostructure catalysts. When copper oxychloride solid precursors were loaded on a conductive electrode, they were partially dissolved near the surface of the electrode during the $\mathrm{CO}_{2}$ electroreduction process. ${ }^{46}$ The dissolved copper ions were then electrochemically redeposited on the surface of the electrode, forming the catalyst layer. Depending on the applied potential, catalysts with different morphologies, including nanoneedles, nanowhiskers, and dendrites and with different oxidation states were achieved (Fig. 10c and d). The in situ deposition of the catalyst under ECR also allows one to control the exposed active facets, which is a critical factor in the design of electrocatalysts. To grow Cu with exposed (100) facets, which are active for $\mathrm{CO}$ dimerization to form $\mathrm{C}_{2+}$ products, $\mathrm{Cu}$ -
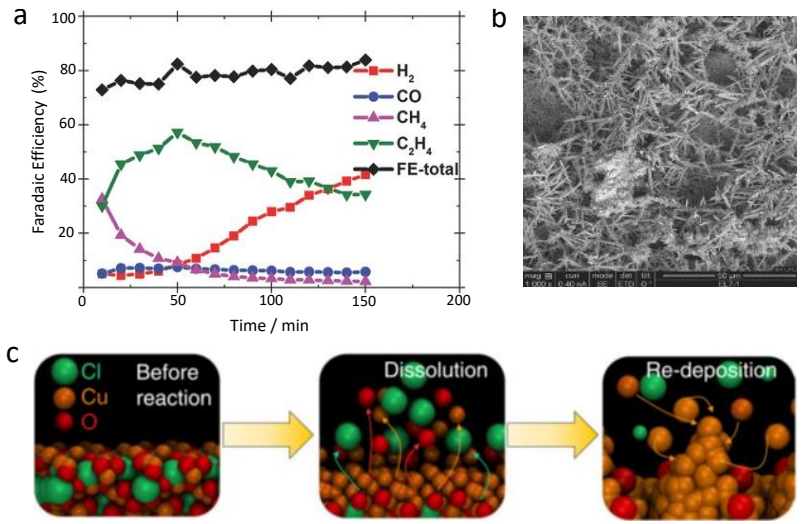

Time $/$ min
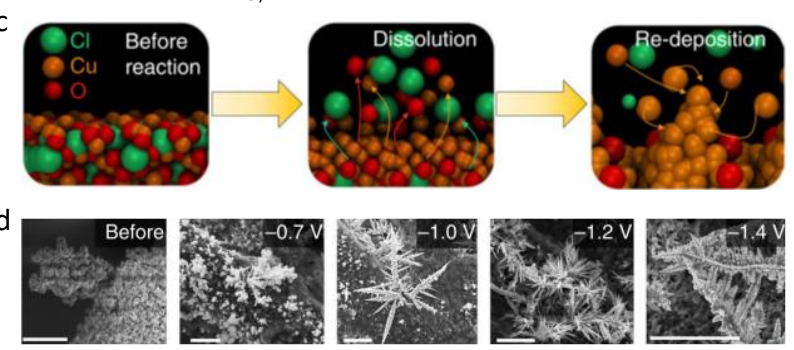

Fig. 10. a) Temporal development of the Faradaic efficiency of gas-phase products during the $\mathrm{CO}_{2}$ electrolysis experiment with in situ nanodeposited copper dendrites in $0.1 \mathrm{M}$ $\mathrm{KBr}$. The experiment was conducted at a current density of $170 \mathrm{~mA} / \mathrm{cm}^{2}$, a maximum Faradaic efficiency of $57 \%$ was observed for ethylene. b) SEM image indicating in situ grown dendritic crystallites on the GDL sheet surface. c) Schematic illustration of the electrogrowth process, whereby simultaneous dissolution and redeposition of Cu results in structured deposits. d) SEM images of the key structure features at their specific applied potentials after at least $1 \mathrm{~h}$ of reaction. Scale bars are $5 \mu \mathrm{m}$. Reproduced from ref. ${ }^{45}$ with permission from Wiley, copyright 2017 , and ref. ${ }^{46}$ with permission from Nature Publishing Group, copyright 2018.

ethylenediaminetetraacetic complex was employed as the precursor and an alkaline solution $(\mathrm{KOH})$ was used as the electrolyte. In situ electrodeposition of the catalysts on a GDL was performed in a flow cell under the presence of $\mathrm{CO}_{2}$ gas reactant. At the optimal synthesis condition, Cu-cube catalysts with a high $\mathrm{Cu}(100)$-to- $\mathrm{Cu}(111)$ surface area ratio were obtained. The catalysts generate $\mathrm{C}_{2+}$ products with maximum Faradaic efficiency for $C_{2+}$ products of $90 \pm 1 \%$ at a partial current density of up to $520 \mathrm{~mA} / \mathrm{cm}^{2}$. It is suggested that the intermediate products of the ECR process can stabilize the $\mathrm{Cu}(100)$ facet, resulting in a catalyst with a highly exposed $\mathrm{Cu}(100)$ surface. ${ }^{35}$

In summary, 3D nanostructured materials exhibiting interesting morphological properties have been demonstrated as efficient catalysts for ECR. Currently, this structure has not been well developed for gas-phase systems. One limitation of 3D nanostructured catalyst layers is their low efficient use of the total catalyst surface area. As discussed above, the $\mathrm{CO}_{2}$ reactant mainly exists near the GDL-catalyst interface. Extended catalyst parts, which are located far from this interface, will operate under a $\mathrm{CO}_{2}$ deficit condition, leading to the formation of the unwanted $\mathrm{H}_{2}$ product. Recent advances in managing the $\mathrm{CO}_{2}$ reactant in the catalyst layer via surface coating would help to overcome this problem, opening an opportunity to fully exploit the advantage of 3D nanostructured catalysts. ${ }^{24}$

\subsubsection{D Nanoparticulate catalyst layer}

3D nanoparticulate structure is a thick layer $(1-10 \mu \mathrm{m})$ composed of an active catalyst phase in close contact with an ionomer as a binder. This is the most common catalyst layer structure in GDEs for gas-phase ECRs. The active catalytic phase 
a

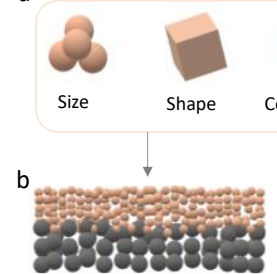

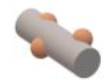

Supported

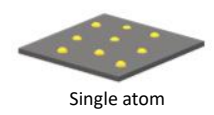

single atom Molecular

Fig. 11. a) Catalysts with various sizes, shapes, compositions, and structures used for the fabrication of efficient 3D nanoparticulate catalyst layers. b)-d) The 3D nanoparticulate catalyst layer (b) can also be constructed in the form of a mixture (c) and layered structure (d).

can be in various sizes, shapes, and compositions. 3D nanoparticulate structures also allow multiple active phases in the form of a mixture and layered structure (Fig. 11). The ionomer in 3D nanoparticulate structures binds the catalyst particles together while transporting the gaseous reactants and ions throughout the catalyst layer. The nature of the active phases, their arrangement, and ionomers can be used as key factors for the fabrication of efficient 3D nanoparticulate catalyst layers.

Fabrication. Unlike the 2D and 3D nanostructured layers where the active catalyst is grown directly on the surface of the GDL, the active phase in the 3D nanoparticulate layer is usually presynthesized before it is coated on the GDL. The process involves mixing pre-synthesized active catalyst particles with a suitable ionomer and solvent, e.g., alcohols, to form a catalyst ink, which is then coated on the GDL via spray or blade coating. ${ }^{22,24,34}$

Spray-coating involves the spraying of catalyst ink with air pressure atomizing spray gun, i.e., airbrush, onto the GDL. The spray droplets formed by pressurized gas often have a broad distribution of diameter and kinetic energy, causing less precise control of diameter and speed. This method is effective when thick layers are needed (e.g., the thickness of the layer is much larger than the size of droplets); however, it may not be suitable for depositing a very thin catalyst layer. Moreover, the operation is manual and relies on the skill of the operator, hence the catalyst layer's properties, e.g., thickness and homogeneity, might not be reproducible. For ECR studies, we believe that employing other advanced spraying techniques such as ultrasonic spray coating or electrospraying that allow for less material usage, reduced roughness, and high homogeneity might be beneficial for high-quality catalyst layers.

Blade coating is the technique in which a knife is used to remove the excess of coating material deposited on the GDL substrate. The thickness of the coating layer can be controlled by the gap between the blade and the substrate. This method provides an efficient way of achieving high precision in catalyst loading and thickness with high reproducibility. Screen printing can also be used for coating the catalyst layer on GDL, which uses a blade moving across the screen that is momentarily in touch with the GDL substrate to push the ink through the screen and deposit the wet ink on the substrate. It is worth noting that in practice, uniform deposition of the catalyst layer is necessary to prevent the exposure of the carbonaceous MPL, which can lead to side reactions as well as damage of the MPL, thus decreasing the performance of the GDE.

Active catalytic phase. In ECR, $\mathrm{CO}_{2}$ molecules and intermediates are adsorbed and converted on the surface of the active catalysts. Tuning the surface and physical properties of the catalyst by changing its structure and composition is therefore critical for catalytic performance improvement. Details about these approaches for the development of the ECR catalyst, predominantly in the aqueous phase, have been welldocumented. $3,5,13$ In gas-phase ECR using flow cells, electrolytes at a wide range of $\mathrm{pH}$ can be used. In addition, at high current densities, the local $\mathrm{pH}$ near the catalyst surface in the gas-phase $E C R$ is often much higher than that in aqueous systems. In this section, we focus on some key phenomena related to the effect of the local reaction environment that should be considered when designing nanoparticulate catalysts for gas-phase ECR.

While the active phase is mainly used to tune the selectivity, controlling the reaction environment can also be used. For example, $\mathrm{Ag}$, known as a highly selective catalyst for $\mathrm{CO}$ formation, can generate formate with a Faradaic efficiency as high as $60 \%$ when the reaction was performed in a highly basic electrolyte $(\mathrm{KOH} 11 \mathrm{M}) .{ }^{9}$ Because hydronium $\left(\mathrm{H}_{3} \mathrm{O}^{+}\right)$plays a key role in lowering the activation energy barrier for $\mathrm{CO}$ formation, its lower concentration makes the formate reaction pathway more favorable than $\mathrm{CO}$. The high local $\mathrm{pH}$ was also found to suppress the competing hydrogen evolution in ECR, providing opportunities to develop the catalyst based on a variety of metals such as $\mathrm{Al}, \mathrm{Ni}, \mathrm{Fe}$, which usually suffer from low $\mathrm{CO}_{2}$ reduction selectivity due to high hydrogen evolution activity. ${ }^{39}$ High local $\mathrm{pH}$ in ECR also favors the coupling of the $\mathrm{CO}$ intermediate, leading to enhanced activity and selectivity towards $\mathrm{C}_{2+}$ products. While this effect has been mainly demonstrated in Cu-based catalysts, it also opens the door to investigate non-Cu based catalysts for producing $\mathrm{C}_{2+}$ products. Wu et al. observed a significant amount of hydrocarbons and oxygenates when $\mathrm{N}$-doped graphene quantum dot catalysts were used and ECR was performed in a $\mathrm{KOH}$ electrolyte (Fig. 12). ${ }^{47}$ In the optimal conditions, multiple carbon products, including ethylene, ethanol, and acetate, can be produced with a total Faradaic efficiency higher than $50 \%$ at a current density higher than $100 \mathrm{~mA} / \mathrm{cm}^{2}$. The combination of the nature of the active material (quantum dots morphology and $\mathrm{N}$-doping effect) and the favorable reaction environment is attributed to this high performance.
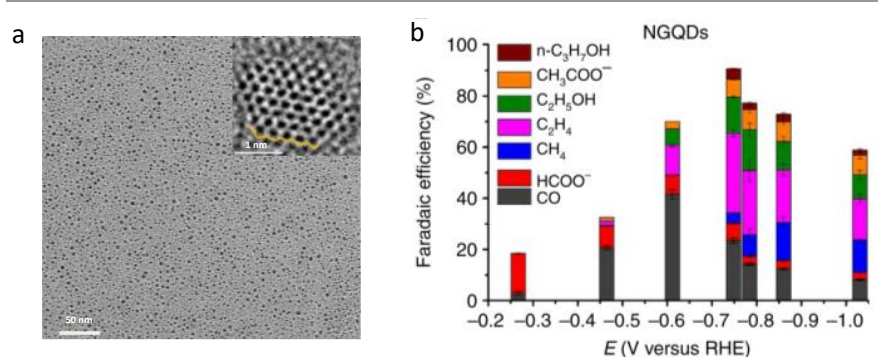

Fig. 12. a) TEM image of $\mathrm{N}$-doped graphene quantum dots. Inset shows a single $\mathrm{N}$-doped graphene quantum dot containing zigzag edges as circled. The yellow line outlines the zigzag edge. Scale bar in inset, $1 \mathrm{~nm}$. b) Faradaic efficiencies of carbon monoxide (CO), methane $\left(\mathrm{CH}_{4}\right)$, ethylene $\left(\mathrm{C}_{2} \mathrm{H}_{4}\right)$, formate $\left(\mathrm{HCOO}^{-}\right)$, ethanol $(\mathrm{EtOH})$, acetate $\left(\mathrm{ACO}^{-}\right)$and $n$ propanol ( $\mathrm{n}$ - $\mathrm{PrOH}$ ) at various applied cathodic potentials for $\mathrm{N}$-doped graphene quantum dots. Reproduced from ref. ${ }^{47}$ with permission from Nature Publishing Group, copyright 2016. 
lonomers. An ionomer is a polymer that contains both electrically neutral and ionized repeating units, e.g., Nafion, and is often used to bind the nanoparticulate catalyst onto the GDL. Although the ionomer is not directly involved in the electrocatalytic reactions, its structure and loading content can have a significant influence on the electroactive surface area, the ionic conductivity, the hydrophilicity/hydrophobicity, and the transport of reactants and ions of the catalyst layer.

In gas-phase $\mathrm{ECR}, \mathrm{CO}_{2}$ reduction mainly occurs within a gasliquid-solid three-phase reaction boundary. Without a gas transport layer, the volume of this interface decays rapidly at high current densities, especially in an alkaline electrolyte (e.g. $\mathrm{KOH}){ }^{24,} 31$ If $\mathrm{CO}_{2}$ and the electrolyte are separately transported to the catalyst surface, the reaction interface will be expanded, allowing high current density operation. Recently, it was found that the Nafion, a perfluorinated sulfonic acid ionomer, improves the gas transport in the catalyst layer (Fig. 13 a). ${ }^{24}$ When Nafion ionomer was coated onto metal catalysts deposited on a porous PTFE substrate, forming a catalyst:ionomer bulk heterojunction ( $\mathrm{ClBH}$ ) architecture (Fig. 13 b-e), the limiting current density for $\mathrm{CO}_{2}$ reduction was significantly increased. In a $5 \mathrm{M} \mathrm{KOH}$ electrolyte, Nafion-coated $\mathrm{Cu}$ exhibited a partial current density toward $\mathrm{CO}$ and ethylene
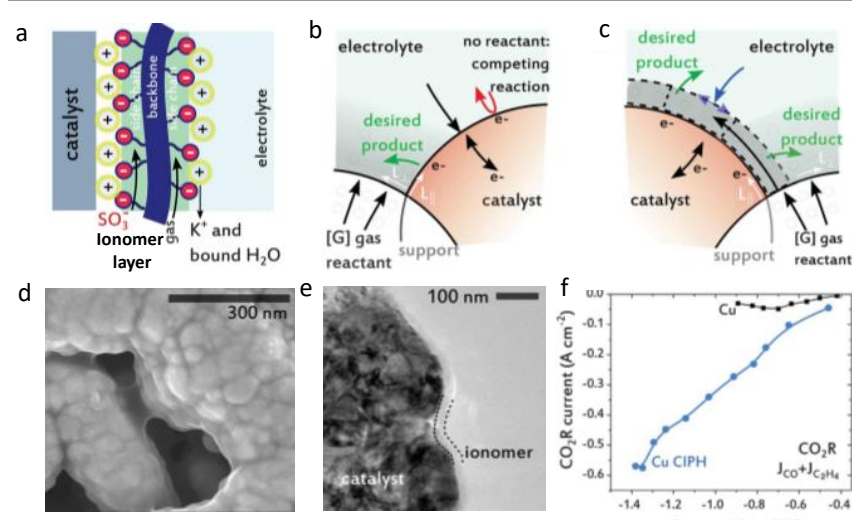

g
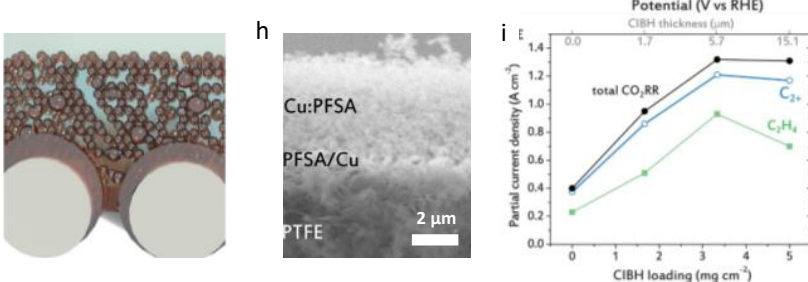

Fig. 13. a) Perfluorinated ionomers such as Nafion exhibit differentiated hydrophilic and hydrophobic characteristics endowed by $-\mathrm{SO}_{3}{ }^{-}$and $-\mathrm{CF}_{2}$ functionalities, respectively. $\mathrm{b}$ The volume in which gas reactants, active sites, and water and ions coexist determines the maximum available current for gas electrolysis. Catalyst regions with limited reactant concentration promote by-product reactions such as hydrogen evolution. c) When gas and electrolyte (water and ion source) transport is decoupled, the three-phase reaction interface can be extended so that all electrons participate in the desired electrochemical reaction. d) SEM image of ionomer-coated copper catalysts. e) Cryo-microtomed TEM cross-sections of catalyst and ionomer revealing a laminar conformal overcoating. f) Limiting current $J_{\text {lim }}$ toward ethylene is $50 \mathrm{~mA} / \mathrm{cm}^{2}$ at $-0.7 \mathrm{~V}$ vs. RHE for bare Cu but increases beyond $0.5 \mathrm{~A} / \mathrm{cm}^{2}$ for $\mathrm{ClPH}$ (peak FE of $61 \%$ at $835 \mathrm{~mA} / \mathrm{cm}^{2}$ ). g) Schematic representation of metal-ionomer bulk heterojunction catalysts on a PTFE support. $h$ ) Cross-sectional SEM of the $\mathrm{CIBH}$ catalyst. i) Partial current density for total $\mathrm{CO}_{2}$ reduction reactions, with $\mathrm{C}_{2+}$ and $\mathrm{C}_{2} \mathrm{H}_{4}$ at maximum cathodic energy efficiency. The total $\mathrm{CO}_{2}$ reduction current saturates at $1.3 \mathrm{~A} / \mathrm{cm}^{2}$ before cathodic energy efficiency drops for $\mathrm{CIBH}$ thicknesses beyond $6 \mathrm{~mm}$. Reproduced from ref. ${ }^{24}$ with permission from AAAS, copyright 2020 of $510 \mathrm{~mA} / \mathrm{cm}^{2}$, which is 10 times higher than the value obtained for bare $\mathrm{Cu}$ (Fig. 13 f). Based on this effect, the CuNafion ratio was optimized for 3D nanoparticulate catalyst layers. An optimal Nafion:Cu weight ratio of 3:4 found to show the highest performance. Also, the optimal thickness of the catalyst found to be around $5 \mu \mathrm{m}$ (Fig. $13 \mathrm{~g}$-i). The optimized catalyst exhibited an ethylene Faradaic efficiency above $65 \%$ and an impressive peak partial current density of $1.34 \mathrm{~A} / \mathrm{cm}^{2}$ at the cathodic energy efficiency of $46 \pm 3 \%$ in a flow-cell using $\mathrm{KOH}$ electrolyte. ${ }^{24}$ In a MEA cell, the optimized catalyst exhibited an ethylene Faradaic efficiency of $50 \%$ at a current density of $200 \mathrm{~mA} / \mathrm{cm}^{2}$. The lower performance obtained in the MEA cell suggests that further optimization of the catalyst structure beyond gas transport is needed for this cell configuration.

Besides the catalyst:ionomer ratio, the types of ionomer also affect ECR performance. Xu et al. studied the effect of ionomers on ECR using a mixture of $\mathrm{O}_{2}$ and $\mathrm{CO}_{2}$ feedstock. ${ }^{48}$ When an ionomer with hydrophilic nanopore was used, the pores are filled with electrolyte during operation, which selectively impedes $\mathrm{O}_{2}$ mass transport without a significant impact on $\mathrm{CO}_{2}$ transport. Since the presence of $\mathrm{O}_{2}$ significantly suppresses the ECR as the oxygen reduction to water becomes the main reaction, the ability to slow $\mathrm{O}_{2}$ transport allowed for direct reduction of a simulated flue gas mixture $\left(\mathrm{O}_{2}\right.$ containing diluted $\mathrm{CO}_{2}$ ) as the feedstock without the need of $\mathrm{O}_{2}$ separation, which in principle could lower the system costs of a $\mathrm{CO}_{2}$ electrolyzer. Employing Sustainion possessing a hydrophilic poly(4-vinylbenzyl alkyl-imidazolium chloride) unit as the hydrophilic ionomer, the author obtained $\mathrm{C}_{2}$ products with $\mathrm{FE}$ of $68 \%$ at a cell potential of $-3.00 \mathrm{~V}$, and the current density and selectivity toward $C_{2}$ products were stable for 10 hours of operation. ${ }^{48}$

Catalyst layer structure. In $\mathrm{CO}_{2}$ electroreduction to hydrocarbons and oxygenates, $\mathrm{CO}$ intermediate is first produced, followed by its dimerization and/or a series of hydrogenation reaction to form final products. The two distinct steps enable the design of a tandem catalyst in which $\mathrm{CO}_{2}$ is first reduced on one catalyst to form $\mathrm{CO}$, which is further converted on another near-by catalyst. For example, when Au clusters were deposited on the surface of $\mathrm{Cu}$, the formation of oxygenates at low overpotential on this catalyst was significantly enhanced compared to that of pure $\mathrm{Cu} .{ }^{49}$ Mass transport modeling suggested that a high $\mathrm{CO}$ concentration on near-by $\mathrm{Cu}$ is generated from the $\mathrm{CO}_{2}$ reduction on Au clusters. This high CO reactant concentration accelerates the formation of ethanol and n-propanol on the Cu catalyst. Recently, Wang et al. found a significant improvement in ethylene production from ECR on $\mathrm{Cu}$ catalysts when a mixture of $\mathrm{CO}_{2}$ and $\mathrm{CO}$ was used as reactants. ${ }^{50}$ The kinetic isotope-labelling experiments reveal a cross-coupled $\mathrm{CO}_{2}-\mathrm{CO}$ reactive pathway which leads to enhanced ethylene production. Based on this finding, the authors developed a tandem catalyst consisting of $\mathrm{Cu}$ catalyst $\left(\mathrm{CuO}_{\mathrm{x}}\right)$ deposited on a single atom Ni-N-doped carbon (NiNC) that is highly active for $\mathrm{CO}_{2}$ reduction to $\mathrm{CO}$ (Fig. 14 a). The ethylene production rate on the $\mathrm{CuO}_{\mathrm{x}}-\mathrm{NiNC}$ tandem catalysts 

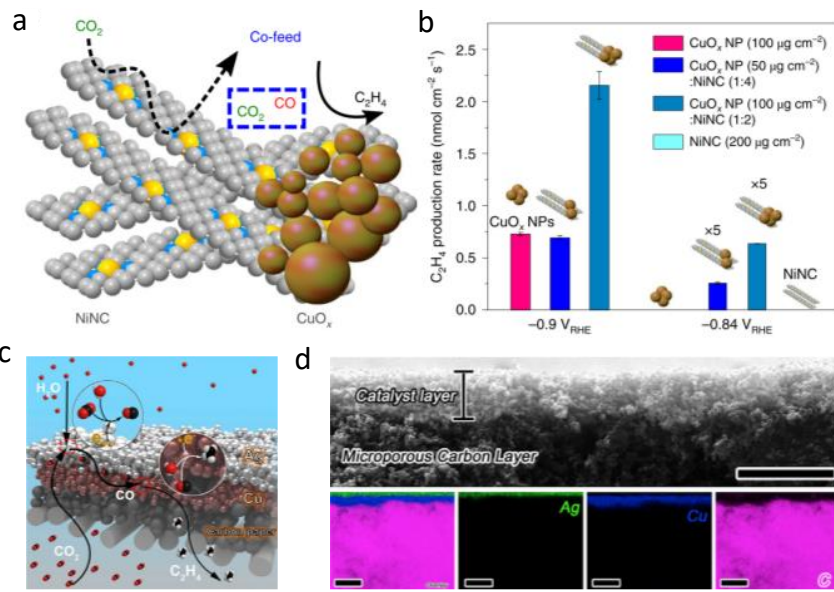

d

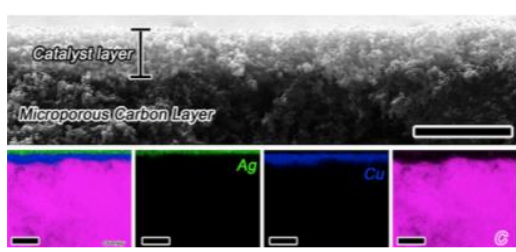

$\mathrm{e}$
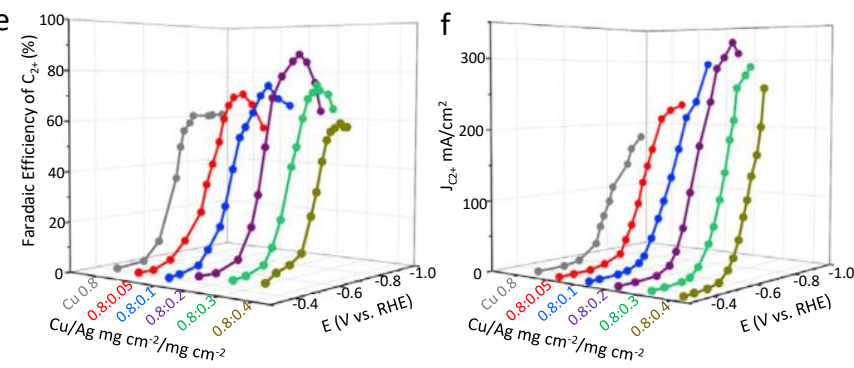

Fig. 14. a) The tandem catalyst design combines NiNC material, as a local CO-producer, and $\mathrm{CuO}_{x}$ nanoparticles on a carbon-paper electrode. Grey, $\mathrm{C}$ atom; Blue, $\mathrm{N}$ atom; Yellow, $\mathrm{Ni}$ atom. b) $\mathrm{C}_{2} \mathrm{H}_{4}$ production rate with the bifunctional hybrid catalyst with carbon paper as a working electrode for $\mathrm{CO}_{2}$ reduction reactions at the various component and fixed overpotentials. The experimental $\mathrm{C}_{2} \mathrm{H}_{4}$ production rates at $-0.84 \mathrm{~V}$ vs. RHE are multiplied by 5 for comparison. No $\mathrm{C}_{2} \mathrm{H}_{4}$ formation is detected on pure $\mathrm{CuO}_{x}$ nanoparticles with areal loading of $100 \mu \mathrm{g} \mathrm{cm}^{-2}$ at $-0.84 \mathrm{~V}$ vs. RHE. No $\mathrm{C}_{2} \mathrm{H}_{4}$ formation is detected on pure NiNC catalysts at both $-0.84 \mathrm{~V}$ and $-0.9 \mathrm{~V}$ vs. RHE. c) Schematic illustration of a two-layer tandem electrode structure and charge transfer and mass transport for the proposed tandem catalysis. d) A cross-sectional SEM image and EDS elemental mapping of a $\mathrm{Cu} / \mathrm{Ag}$ tandem electrode with two catalyst layers. Scale bars: $4 \mathrm{~mm}$ for the SEM image and $5 \mathrm{~mm}$ for the elemental mapping. e) and f) Comparison of (e) faradaic efficiency of $C_{2+}$ products and ( $f$ ) partial current density of $\mathrm{C}_{2+}$ on various $\mathrm{Cu} / \mathrm{Ag}$ tandem electrodes with a fixed Cu loading of $0.8 \mathrm{mg} \mathrm{cm}^{-2}$ but variable Ag loading ranging from 0.05 to $0.4 \mathrm{mg} \mathrm{cm}^{-2}$. Reproduced from ref. ${ }^{33}$ with permission from Elsevier, copyright 2020, and from ref. ${ }^{50}$ with permission from Nature Publishing Group, copyright 2019.

was significantly higher than that on pure $\mathrm{CuO}_{x}$ (Fig. 14b). With an optimal $\mathrm{CuO}_{x}$ :NiNC ratio, a three-fold increase in ethylene production rate was observed at an applied potential of $-0.9 \mathrm{~V}$ vs. RHE. ${ }^{50}$

Besides nanoscale supported tandem catalysts, a layered tandem structure where the two active materials are located in two distinct layers has been developed recently. For example, She et al., explored tandem catalysts made of one $\mathrm{CO}_{2}$-to- $\mathrm{CO}$ catalyst $(\mathrm{Ag}, \mathrm{Au}, \mathrm{NiNC})$ and $\mathrm{Cu}$ catalyst with either mixed or layer structures. ${ }^{33}$ The authors found that the tandem catalysts showed the highest $\mathrm{C}_{2+}$ production when the $\mathrm{Cu}$ catalyst was first deposited on GDL, followed by the deposition of the $\mathrm{CO}_{2-}$ to-CO catalyst (Fig. $14 \mathrm{c}$ and d). In this configuration, the $\mathrm{CO}$ produced on the outer catalyst layer is diffused back to the $\mathrm{Cu}$ catalyst layer, producing a high flux of $\mathrm{CO}$ flow to be reduced by the $\mathrm{Cu}$ catalyst. By balancing the rate of $\mathrm{CO}$ production and $\mathrm{CO}$ reduction via tuning the loadings of the two respective catalysts, the $\mathrm{C}_{2+}$ production rate was significantly improved
(Fig. 14 e and f). The optimal $\mathrm{Cu} / \mathrm{Ag}$ catalysts exhibited a total $\mathrm{C}_{2+}$ Faradaic efficiency of up to $85 \%$ (compared to $60 \%$ on pure $\mathrm{Cu}$ ) at a partial current density higher than $300 \mathrm{~mA} / \mathrm{cm}^{2}{ }^{33}$ When a MEA cell was used, the tandem catalyst layer also exhibited a good ethylene Faradaic efficiency (48\%), albeit a bit lower compared to that in flow cell configuration (>60\%).

Overall, 3D nanoparticulate catalyst layers represent the most feasible structure for practical applications. It combines the advances in the fabrication of nanoscale catalytic materials using various physical and chemical methods and knowledge in catalyst layer deposition in fuel cell and electrolyzer technology. However, the transport mechanism of $\mathrm{CO}_{2}$, water, and ions in the 3D catalyst layer is still unclear. One important question is whether the catalyst layer is fully filled with water and electrolyte during the $\mathrm{CO}_{2}$ reduction reaction. It is also unclear if the $\mathrm{CO}_{2}$ reduction reaction takes place predominantly at the gas-liquid-solid triple-phase interface or at the gas-liquid interface adjacent to the catalyst surface. Understanding the structures and roles of the ionomers is critical to those questions. While ionomers have significantly improved the limiting current density in ECR, clear experimental evidence is needed to know whether they improve the $\mathrm{CO}_{2}$ gas transport, or they extend the triple-phase reaction area in the catalyst layer. In addition, the formation of alcohol products in ECR can affect the gas transport in the catalyst layer by filling the hydrophobic pores in the ionomer (i.e., Nafion) or eliminating them from the catalyst layer. Understanding these phenomena and developing more stable and efficient catalysts would further advance ECR technology, especially for producing hydrocarbons and oxygenates.

\section{Summary and outlook}

Fossil fuels have been and will continue to be the main energy resource in the near future. The development and expansion of renewable energy sources, carbon capture and sequestration, and especially the catalytic conversion of $\mathrm{CO}_{2}$ into chemicals and fuels are necessary for $\mathrm{CO}_{2}$ mitigation. The ECR technology fits well into this context as it produces value-added products from $\mathrm{CO}_{2}$ while providing a long-term and large-scale storage solution for intermittent renewable energies. In this review, we cover the development of the GDE, the most important component in ECR systems. We highlight the principles underlying recent high-performance GDEs, focusing on how the structure and composition of each individual component of GDE affect the overall performance of the electrode.

Despite significant advances in the last few years, the performance of ECR is still far from the desired values to be economically feasible, especially the stability and energy efficiency for the production of $\mathrm{C}_{2+}$ products. The most stable $\mathrm{CO}_{2}$-to- $\mathrm{C}_{2+} \mathrm{ECR}$ system operating at a current density higher than $100 \mathrm{~mA} / \mathrm{cm}^{2}$ maintained its performance for only a few hundred hours, while practical applications would require stability of tens of thousands of hours. The energy efficiency of the ECR system for $\mathrm{C}_{2+}$ products remains below $40 \%$, far below the value that makes this technology viable $(60 \%-70 \%) .{ }^{1}$ While the performance of other components, including anode and 
membrane, also contributes to the overall performance of ECR, GDE is the main driver of the viability of the ECR, so boosting its performance remains a crucial task. Achieving this goal requires understanding and rationally design of the GDEs, including the compositions, morphologies, and structures of their components.

Stable GDLs for hydrocarbon and oxygenate production remain an unsolved problem in ECR. Current carbon-based GDLs exhibit decreased performance after a few tens of hours of operation. The strategy that decouples the hydrophobic and current collection requirements of traditional carbon-based GDLs has allowed for improving the stability of GDEs to hundreds of hours; however, new design in the current collector is needed for a large-scale system. Next-generation GDLs that can maintain their stable performance at high current densities and in the presence of hydrocarbons and oxygenate are the requirements to move the ECR technology forward. In this context, a PTFE coated porous metal foam exhibiting high electrical conductivity and high surface hydrophobicity would be a good system to investigate.

Developing an active and selective catalyst remains a crucial step in designing efficient GDEs. Currently, $\mathrm{Cu}$ is the only known metal that reduces $\mathrm{CO}_{2}$ to $\mathrm{C}_{2+}$ with good selectivity. However, its large overpotential contributes to the low overall energy efficiency of ECR. Further development of efficient catalysts requires insights into the reaction mechanism and detailed understanding of the structure-performance relationship. The combination of experimental and computational studies has been used to shed light on the mechanisms of ECR, by providing atomic-level detail of reaction steps and energy levels of intermediates. ${ }^{13}$ It will continue to be crucial for further improving the performance of the catalysts. However, because the local reaction environment in the GDE is drastically different from that in the aqueous system, mass transport modeling should be included in the theoretical model to understand the change and effect of the environment. Multi-scale modeling, which integrates atomistic and continuum-scale models, would thus be a powerful tool for GDE development.

Operando characterization tools, which provide real-time insight into the reaction intermediates and the material evolution during the reaction, have been successfully employed in aqueous ECR. ${ }^{11}$ These tools will continue to play an important part in developing high-performance GDEs. For example, operando spectroscopies such as Infrared and Raman can be used to understand the distribution of reaction area and phase boundary in the catalyst layer. Thus, they would provide insights that may lead to better GDE design for practical ECR. Techniques that have been widely used to characterize GDEs of fuel cells and electrolyzers such as computed X-ray tomography can be adopted to study GDEs for ECR. This powerful technique that enables real-time tracking of the catalyst particles and the ionomer, as well as the migration of water in the GDE would be of great value for understanding its degradation. Because of its complex structure, identifying the degradation mode of each component in GDE would be challenging. In this context, accelerated testing in which different stresses can be used to target the performance of each component in GDE would be necessary. Therefore, coupling operando characterization techniques with accelerated testing would further advance the ECR technology.

\section{Conflicts of interest}

There are no conflicts to declare

\section{Acknowledgements}

T.N.N acknowledges the support from Helen Co., Ltd. C.T.D acknowledges the financial support from the Natural Sciences and Engineering Research Council of Canada (NSERC) and Queen's University.

\section{Abbreviations}

ECR: Electrochemical $\mathrm{CO}_{2}$ Reduction

GDE: Gas Diffusion Electrode

GDL: Gas Diffusion Layer

AEM: Anionic-Exchange Membrane

CEM: Cation-Exchange Membrane

BPM: Bipolar Membrane

OER: Oxygen Evolution Reaction

MEA: Membrane Electrode Assembly

MPS: Macroporous Substrate

MPL: Microporous Layer

PTFE: Polytetrafluoroethylene

RHE: Reversible Hydrogen Electrode

CIBH: Catalyst:Ionomer Bulk Heterojunction

\section{Notes and references}

1. P. De Luna, C. Hahn, D. Higgins, S. A. Jaffer, T. F. Jaramillo and E. H. Sargent, Science, 2019, 364, eaav3506.

2. C. Hepburn, E. Adlen, J. Beddington, E. A. Carter, S. Fuss, N. Mac Dowell, J. C. Minx, P. Smith and C. K. Williams, Nature, 2019, 575, 87.

3. M. G. Kibria, J. P. Edwards, C. M. Gabardo, C.-T. Dinh, A. Seifitokaldani, D. Sinton and E. H. Sargent, Adv. Mater., 2019, 31, 1807166 (and references therein).

4. S. Nitopi, E. Bertheussen, S. B. Scott, X. Liu, A. K. Engstfeld, S. Horch, B. Seger, I. E. L. Stephens, K. Chan, C. Hahn, J. K. Nørskov, T. F. Jaramillo and I. Chorkendorff, Chem. Rev., 2019, 119, 7610

5. M. B. Ross, P. De Luna, Y. Li, C.-T. Dinh, D. Kim, P. Yang and E. H. Sargent, Nat. Catal., 2019, 2, 648.

6. D. M. Weekes, D. A. Salvatore, A. Reyes, A. Huang and C. P. Berlinguette, Acc. Chem. Soc., 2018, 51, 910.

7. C.-T. Dinh, T. Burdyny, M. G. Kibria, A. Seifitokaldani, C. M. Gabardo, F. P. G. de Arquer, A. Kiani, J. P. Edwards, P. De Luna and O. S. Bushuyev, Science, 2018, 360, 783.

8. D. Higgins, C. Hahn, C. Xiang, T. F. Jaramillo and A. Z. Weber, ACS Energy Lett., 2019, 4, 317 (and references therein).

9. A. Seifitokaldani, C. M. Gabardo, T. Burdyny, C.-T. Dinh, J. P. Edwards, M. G. Kibria, O. S. Bushuyev, S. O. Kelley, D. Sinton and E. H. Sargent, J. Am. Chem. Soc., 2018, 140, 3833. 
10. Y. Y. Birdja, E. Pérez-Gallent, M. C. Figueiredo, A. J. Göttle, F. Calle-Vallejo and M. T. M. Koper, Nat. Energy, 2019, 4, 732.

11. D. Gao, R. M. Arán-Ais, H. S. Jeon and B. Roldan Cuenya, Nat. Catal., 2019, 2, 198.

12. M. R. Singh, Y. Kwon, Y. Lum, J. W. Ager and A. T. Bell, J. Am. Chem. Soc., 2016, 138, 13006.

13. Z. W. Seh, J. Kibsgaard, C. F. Dickens, I. Chorkendorff, J. K. Nørskov and T. F. Jaramillo, Science, 2017, 355, eaad4998.

14. B. Zhang, X. Zheng, O. Voznyy, R. Comin, M. Bajdich, M. GarcíaMelchor, L. Han, J. Xu, M. Liu, L. Zheng, F. P. García de Arquer C. T. Dinh, F. Fan, M. Yuan, E. Yassitepe, N. Chen, T. Regier, P. Liu, Y. Li, P. De Luna, A. Janmohamed, H. L. Xin, H. Yang, A. Vojvodic and E. H. Sargent, Science, 2016, 352, 333.

15. X. Lu and C. Zhao, Nat. Commun., 2015, 6, 6616.

16. X. Zheng, B. Zhang, P. De Luna, Y. Liang, R. Comin, O. Voznyy, L. Han, F. P. García de Arquer, M. Liu, C. T. Dinh, T. Regier, J. J. Dynes, S. He, H. L. Xin, H. Peng, D. Prendergast, X. Du and E. H. Sargent, Nat. Chem., 2017, 10, 149.

17. F. Li, A. Thevenon, A. Rosas-Hernández, Z. Wang, Y. Li, C. M. Gabardo, A. Ozden, C. T. Dinh, J. Li, Y. Wang, J. P. Edwards, Y. Xu, C. McCallum, L. Tao, Z.-Q. Liang, M. Luo, X. Wang, H. Li, C. P. O'Brien, C.-S. Tan, D.-H. Nam, R. Quintero-Bermudez, T.-T. Zhuang, Y. C. Li, Z. Han, R. D. Britt, D. Sinton, T. Agapie, J. C. Peters and E. H. Sargent, Nature, 2020, 577, 509.

18. C. M. Gabardo, C. P. O'Brien, J. P. Edwards, C. McCallum, Y. Xu, C.-T. Dinh, J. Li, E. H. Sargent and D. Sinton, Joule, 2019, 3, 2777.

19. T. Zheng, K. Jiang, N. Ta, Y. Hu, J. Zeng, J. Liu and H. Wang, Joule, 2019, 3, 265.

20. W. Luc, J. Rosen and F. Jiao, Catal. Today, 2017, 288, 79.

21. L.-C. Weng, A. T. Bell and A. Z. Weber, Energy Environ. Sci., 2019, 12, 1950

22. M. Jouny, W. Luc and F. Jiao, Nat. Catal., 2018, 1, 748.

23. Y. C. Li, D. Zhou, Z. Yan, R. H. Gonçalves, D. A. Salvatore, C. P. Berlinguette and T. E. Mallouk, ACS Energy Lett., 2016, 1, 1149.

24. F. P. García de Arquer, C.-T. Dinh, A. Ozden, J. Wicks, C. McCallum, A. R. Kirmani, D.-H. Nam, C. Gabardo, A. Seifitokaldani, X. Wang, Y. C. Li, F. Li, J. Edwards, L. J. Richter, S. J. Thorpe, D. Sinton and E. H. Sargent, Science, 2020, 367, 661.

25. M. G. Kibria, C.-T. Dinh, A. Seifitokaldani, P. De Luna, T. Burdyny, R. Quintero-Bermudez, M. B. Ross, O. S. Bushuyev, F. P. García de Arquer, P. Yang, D. Sinton and E. H. Sargent, Adv. Mater., 2018, 30, 1804867.

26. C. M. Gabardo, A. Seifitokaldani, J. P. Edwards, C.-T. Dinh, T. Burdyny, M. G. Kibria, C. O'Brien, E. H. Sargent and D. Sinton, Energy Environ. Sci., 2018, 11, 2531.

27. C.-T. Dinh, F. P. García de Arquer, D. Sinton and E. H. Sargent ACS Energy Lett., 2018, 3, 2835

28. C. Xia, P. Zhu, Q. Jiang, Y. Pan, W. Liang, E. Stavitski, H. N. Alshareef and H. Wang, Nat. Energy, 2019, 4, 776

29. M. K. Debe, Nature, 2012, 486, 43 (and references therein).

30. X. Wang, Z. Wang, F. P. García de Arquer, C.-T. Dinh, A. Ozden, Y. C. Li, D.-H. Nam, J. Li, Y.-S. Liu, J. Wicks, Z. Chen, M. Chi, B. Chen, Y. Wang, J. Tam, J. Y. Howe, A. Proppe, P. Todorović, F. Li, T.-T. Zhuang, C. M. Gabardo, A. R. Kirmani, C. McCallum, S. F. Hung, Y. Lum, M. Luo, Y. Min, A. Xu, C. P. O’Brien, B. Stephen, B. Sun, A. H. Ip, L. J. Richter, S. O. Kelley, D. Sinton and E. H. Sargent, Nat. Energy, 2020, 5, 478.

31. T. Burdyny and W. A. Smith, Energy Environ. Sci., 2019, 12, 1442 (and references therein).

32. N. Furuya, T. Yamazaki and M. Shibata, J. Electroanal. Chem. 1997, 431, 39.
33. X. She, T. Zhang, Z. Li, H. Li, H. Xu and J. Wu, Cell Rep. Phys. Sci., 2020, 1, 100051.

34. W. Ma, S. Xie, T. Liu, Q. Fan, J. Ye, F. Sun, Z. Jiang, Q. Zhang, J. Cheng and Y. Wang, Nat. Catal., 2020, 3, 478.

35. Y. Wang, Z. Wang, C.-T. Dinh, J. Li, A. Ozden, M. Golam Kibria, A. Seifitokaldani, C.-S. Tan, C. M. Gabardo, M. Luo, H. Zhou, F. Li, Y. Lum, C. McCallum, Y. Xu, M. Liu, A. Proppe, A. Johnston, P. Todorovic, T.-T. Zhuang, D. Sinton, S. O. Kelley and E. H. Sargent, Nat. Catal., 2020, 3, 98.

36. Y. C. Tan, K. B. Lee, H. Song and J. Oh, Joule, 2020, 4, 1104.

37. M. Luo, Z. Wang, Y. C. Li, J. Li, F. Li, Y. Lum, D.-H. Nam, B. Chen, J. Wicks, A. Xu, T. Zhuang, W. R. Leow, X. Wang, C.-T. Dinh, Y. Wang, Y. Wang, D. Sinton and E. H. Sargent, Nat. Commun., 2019, 10, 5814.

38. Y. C. Li, Z. Wang, T. Yuan, D.-H. Nam, M. Luo, J. Wicks, B. Chen, J. Li, F. Li and F. P. Garcia de Arquer, J. Am. Chem. Soc., 2019, $141,8584$.

39. M. Zhong, K. Tran, Y. Min, C. Wang, Z. Wang, C.-T. Dinh, P. De Luna, Z. Yu, A. S. Rasouli, P. Brodersen, S. Sun, O. Voznyy, C.-S. Tan, M. Askerka, F. Che, M. Liu, A. Seifitokaldani, Y. Pang, S.-C. Lo, A. Ip, Z. Ulissi and E. H. Sargent, Nature, 2020, 581, 178.

40. M. Liu, Y. Pang, B. Zhang, P. De Luna, O. Voznyy, J. Xu, X. Zheng, C. T. Dinh, F. Fan, C. Cao, F. P. G. de Arquer, T. S. Safaei, A. Mepham, A. Klinkova, E. Kumacheva, T. Filleter, D. Sinton, S. O. Kelley and E. H. Sargent, Nature, 2016, 537, 382.

41. T. Saberi Safaei, A. Mepham, X. Zheng, Y. Pang, C.-T. Dinh, M. Liu, D. Sinton, S. O. Kelley and E. H. Sargent, Nano Lett., 2016, 16, 7224.

42. J. Rosen, G. S. Hutchings, Q. Lu, R. V. Forest, A. Moore and F. Jiao, ACS Catal., 2015, 5, 4586.

43. A. Dutta, C. E. Morstein, M. Rahaman, A. Cedeño López and P. Broekmann, ACS Catal., 2018, 8, 8357.

44. T. T. H. Hoang, S. Verma, S. Ma, T. T. Fister, J. Timoshenko, A. I. Frenkel, P. J. A. Kenis and A. A. Gewirth, J. Am. Chem. Soc., 2018, 140, 5791.

45. C. Reller, R. Krause, E. Volkova, B. Schmid, S. Neubauer, A. Rucki, M. Schuster and G. Schmid, Adv. Energy Mater., 2017, 7, 1602114.

46. P. De Luna, R. Quintero-Bermudez, C.-T. Dinh, M. B. Ross, O. S. Bushuyev, P. Todorović, T. Regier, S. O. Kelley, P. Yang and E. H. Sargent, Nat. Catal., 2018, 1, 103.

47. J. Wu, S. Ma, J. Sun, J. I. Gold, C. Tiwary, B. Kim, L. Zhu, N. Chopra, I. N. Odeh, R. Vajtai, A. Z. Yu, R. Luo, J. Lou, G. Ding, P. J. A. Kenis and P. M. Ajayan, Nat. Commun., 2016, 7, 13869.

48. Y. Xu, J. P. Edwards, J. Zhong, C. P. O'Brien, C. M. Gabardo, C. McCallum, J. Li, C.-T. Dinh, E. H. Sargent and D. Sinton, Energy Environ. Sci., 2020, 13, 554.

49. C. G. Morales-Guio, E. R. Cave, S. A. Nitopi, J. T. Feaster, L. Wang, K. P. Kuhl, A. Jackson, N. C. Johnson, D. N. Abram, T. Hatsukade, C. Hahn and T. F. Jaramillo, Nat. Catal., 2018, 1, 764.

50. X. Wang, J. F. de Araújo, W. Ju, A. Bagger, H. Schmies, S. Kühl, J. Rossmeisl and P. Strasser, Nat. Nano., 2019, 14, 1063. 